Article

\title{
Influence of Road Excitation and Steering Wheel Input on Vehicle System Dynamic Responses
}

\author{
Zhen-Feng Wang ${ }^{1}$, Ming-Ming Dong ${ }^{1}$, Liang Gu ${ }^{1}$, Jagat-Jyoti Rath ${ }^{2}$, Ye-Chen Qin ${ }^{1, *}$ and \\ Bin Bai ${ }^{3}$ \\ 1 School of Mechanical Engineering, Beijing Institute of Technology, Beijing 100081, China; \\ wangzhenfeng612@gmail.com (Z.-F.W.); vdmm@bit.edu.cn (M.-M.D.); guliangbit@gmail.com (L.G.) \\ 2 LAMIH UMR CNRS 8201, University of Valenciennes, 59314 Valenciennes, France; \\ jagatjyoti.rath@gmail.com \\ 3 College of Mechanical Engineering \& Applied Electronics Technology, Beijing University of Technology, \\ Beijing 100024, China; baibin@126.com \\ * Correspondence: qinyechenbit@gmail.com; Tel.: +86-134-2636-1062
}

Academic Editor: Giuseppe Lacidogna

Received: 23 March 2017; Accepted: 26 May 2017; Published: 2 June 2017

\begin{abstract}
Considering the importance of increasing driving safety, the study of safety is a popular and critical topic of research in the vehicle industry. Vehicle roll behavior with sudden steering input is a main source of untripped rollover. However, previous research has seldom considered road excitation and its coupled effect on vehicle lateral response when focusing on lateral and vertical dynamics. To address this issue, a novel method was used to evaluate effects of varying road level and steering wheel input on vehicle roll behavior. Then, a 9 degree of freedom (9-DOF) full-car roll nonlinear model including vertical and lateral dynamics was developed to study vehicle roll dynamics with or without of road excitation. Based on a 6-DOF half-car roll model and 9-DOF full-car nonlinear model, relationship between three-dimensional (3-D) road excitation and various steering wheel inputs on vehicle roll performance was studied. Finally, an E-Class (SUV) level car model in CARSIM $^{\circledR}$ was used, as a benchmark, with and without road input conditions. Both half-car and full-car models were analyzed under steering wheel inputs of $5^{\circ}, 10^{\circ}$ and $15^{\circ}$. Simulation results showed that the half-car model considering road input was found to have a maximum accuracy of $65 \%$. Whereas, the full-car model had a minimum accuracy of $85 \%$, which was significantly higher compared to the half-car model under the same scenario.
\end{abstract}

Keywords: dynamics modeling; 3-D road excitation; vehicle roll; $\mathrm{CARSIM}^{\circledR}$ simulation

\section{Introduction}

Vehicle roll behavior plays an important role in vehicle safety. Vehicle roll and rollover has been recognized as a vehicle crash type with the highest fatality. According to the National Highway Traffic Safety Administration (NHTSA) [1], vehicle roll or rollover occurred in 3\% of all passenger-vehicle crashes in 2002, and 33\% of all fatalities were related to vehicle roll. Although number of fatalities has been reduced over the last ten years, roll behavior still accounts for a large proportion of all deaths [2]. Hence, it is essential to carry out an in-depth study to understand vehicle roll behavior, which allows further improvement in passenger safety.

In recent years, studies reported in literature on vehicle roll behavior have mainly focused on detection systems and prevention/control algorithms. Yim [2] proposed a 3 degree of freedom (3-DOF) vehicle roll model to design a robust controller to prevent rollover and demonstrated effectiveness of the controller to prevent rollover using simulation with the nonlinear multi-body dynamics simulation CARSIM $^{\circledR}$ software. Yi et al. [3] proposed an estimator based on a 3-DOF vehicle roll model and a 
4-DOF half-car suspension model to obtain vehicle roll angle and roll rate while driving. In addition, a rollover index was used to indicate rollover danger, which was computed using measured lateral acceleration and yaw rate estimated roll angle and roll rate. Rajamani et al. [4,5] proposed a sensor fusion algorithm based on a 3-DOF vehicle roll model to estimate roll angle and center of gravity (C.G.) height. Experimental data was used to confirm performance reliability of developed algorithms in different maneuvers such as constant steering, ramp steering, double lane change and sine with dwell steering tests. Chen et al. [6] proposed an anti-rollover control algorithm based on a 3-DOF vehicle roll model to calculate Time-To-Rollover (TTR) in real-time. Larish et al. [7] developed a new predictive lateral load transfer ratio (PLTR) based a 4-DOF vehicle roll model, which utilized the driver's steering input and several other sensor signals available from the vehicle's electronic stability control system. This new PLTR index provided a time-advanced measurement of rollover propensity, thereby, offering significant benefits for closed-loop rollover prevention. Imine et al. [8] proposed an approach based on a 5-DOF vehicle roll model to estimate vertical forces affecting a vehicle using high-order sliding-mode (HOSM) observes. Employing previously estimated vertical forces; lateral rollover indicating rollover status was determined. Westhuizen et al. [9] proposed possibility of using slow active suspension control to reduce body roll and thus reducing rollover propensity. From the previous work reported in literature, it can be showed that an accurate model is required to approximate actual behavior.

From the discussion above, it can be seen that a majority of the vehicle roll dynamics models were established without considering road excitation and its coupling effects between vertical and lateral dynamics, i.e., no road input. This is in fact an important factor, as real roads are complex and in practice vehicle movements should be considered as variants.

To solve the above-mentioned problems, following two contributions are taken into account in this paper:

- Influence of three-dimensional (3-D) road profile excitation on vehicle lateral and vertical coupling model is studied using half-car and full-car roll models.

- Coupling relationship between the lateral and vertical dynamics using full car models is illustrated for various steering wheel step angle inputs and different road excitation conditions.

The above contributions were validated using $\operatorname{CARSIM}^{\circledR}$, which has a high-fidelity nonlinear 9-DOF vehicle model.

In this paper, a comprehensive analysis considering road excitation and steering wheel input for vehicle roll behavior based on a 6-DOF half-car and a 9-DOF full-car model is proposed. For this analysis, first, a 3-D road profile based on power spectral density (PSD) was developed under straight and steering conditions. Next, 6-DOF and 9-DOF models were constructed under various road conditions. Then, vehicle roll responses using proposed models were obtained with or without the presence of road excitation and various steering wheel input. Finally, CARSIM $^{\circledR}$ was utilized to validate the proposed 6-DOF and 9-DOF models. Results show that vehicle roll performance of 9-DOF model had a significantly higher accuracy than the 6-DOF roll model, especially in presence of road excitation and large steering wheel input.

In order to further illustrate functional relationships between road excitation and vehicle dynamics model, an approach which formulates a relationship between road level and steering wheel input is formulated in this paper. The paper is organized as follows. In Section 2, a 3-D road profile excitation model is briefly presented. Rollover index is illustrated in Section 3. In Section 4, vehicle dynamics of 6-DOF and 9-DOF models are studied. Section 5 deals with validation of the proposed models using CARSIM $^{\circledR}$ for various road excitations and different steering wheel input. Finally, Section 6 concludes the paper. 


\section{Road Excitation Model}

\subsection{Parameter Optimization for Power Spectral Density}

Distance between road surface and base plate is typically defined as a function of road irregularities. Road profile is typically assumed to be homogeneous and isotropic Gaussian random process, and its statistical characteristics can be described by PSD. According to the International Standards Organization (ISO) 8601 [10], PSD of road roughness can be defined as Equation (1).

$$
G_{q}(n)=G_{q}\left(n_{0}\right)\left(\frac{n}{n_{0}}\right)^{-w}
$$

where $n$ is spatial frequency in $m^{-1}, n_{0}$ is reference spatial frequency with a value of $0.1 m^{-1}, G_{q}\left(n_{0}\right)$ is PSD value for reference spatial frequency in $m^{3}, w$ is termed waviness, and reflects approximate frequency structure of the road profile, commonly taken as $w=2$. Also, $G_{q}\left(n_{0}\right)$ represents different road levels ranging from $A$ (very good) to $H$ (very poor), depending on its values.

Equation (1) leads to estimation errors (overrated phenomenon) especially at low frequencies. To deal with this problem, PSD of road roughness based on rational white noise signal is proposed [11], and Equation (1) can be modified as follows.

$$
G_{q}(n)=\frac{\alpha \rho^{2}}{\pi\left(\alpha^{2}+n^{2}\right)}
$$

where $\alpha$ is constant related to road feature; $\rho^{2}$ represents variance of road roughness and $n$ is spatial frequency in $m^{-1}$. More details are stated in [12].

Time domain representation of the road can be given as [11].

$$
\dot{q}(t)=-\alpha v q(t)+w(t)
$$

where, $v$ represents velocity of the vehicle in $\mathrm{m} / \mathrm{s}$ and $w(t)$ is the white noise sequence. Covariance of white noise can be obtained as follows.

$$
\operatorname{cov}[w(t)]=E[w(t) w(t+\tau)]=2 \rho^{2} \alpha v \delta(\tau)
$$

where $\tau$ represents time-shift in $s$ and $\delta(\tau)$ is impulse function.

Then, the method of Least squares nonlinear parameter estimation is used to optimize the road parameters, and the following equation was utilized.

$$
J=\sum_{i=1}^{N}\left[\Phi\left(n_{i}, \alpha, \rho\right)-G_{q}\left(n_{i}\right)\right]^{2} \rightarrow \min
$$

where $N$ is the number of spatial frequency and $n_{i}$ is the sampling frequency points.

Using the ISO-8601 [10], we know that PSD of road roughness is four times for adjacent road levels. We obtain information to other road information based on one of them road parameter.

Based on the above analysis, optimal parameters for varying road level are listed in Table 1.

Considering values presented in [12], PSD of road roughness between rational white noise and ISO standard are compared using Equations (1)-(3). PDS road roughness results are shown in Figure 1.

It can be seen from Figure 1 that PSD of road roughness generated between rational white noise and ISO standard are consistent. 
Table 1. Estimated results of road parameters.

\begin{tabular}{cccc}
\hline Road Level & $\alpha /\left(\mathbf{m}^{-\mathbf{1}}\right)$ & $\rho / \mathbf{m}$ & $G_{q}\left(n_{0}\right)$ \\
\hline$A$ & & 0.0153 & 16 \\
$B$ & & 0.0306 & 64 \\
$C$ & & 0.0611 & 256 \\
$D$ & 0.1222 & 1024 \\
$E$ & 0.0011 & 0.2444 & 4096 \\
$F$ & & 0.4888 & 16,384 \\
$G$ & & 0.9776 & 65,536 \\
$H$ & & 1.9552 & 26,2144 \\
\hline
\end{tabular}

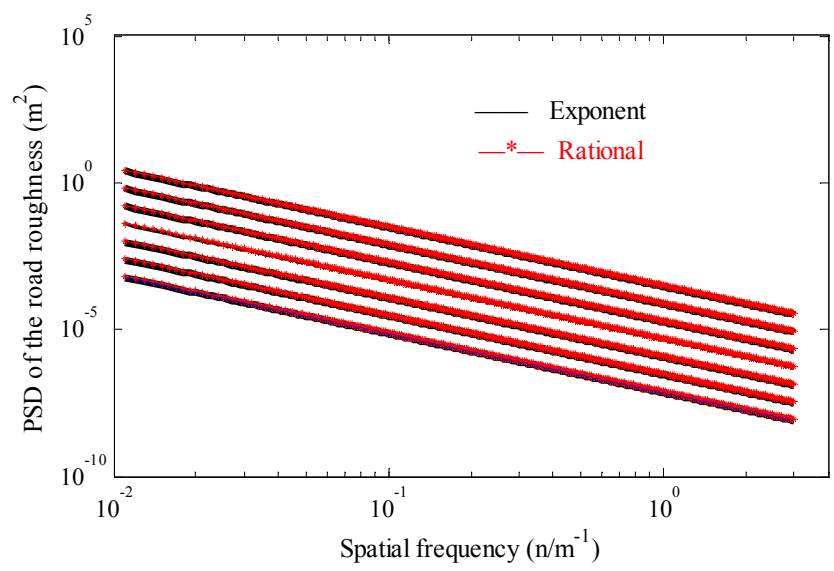

Figure 1. Results of parameters estimation.

\subsection{3-D Road Roughness}

\subsubsection{Straight Driving Condition}

One dimensional (1-D) autocorrelation function of the road roughness PSD based on white noise can be acquired using inverse Fourier transform [13]. 2-D auto-correlation function can be obtained by expanding the 1-D auto-correlation function and using isotropy of road roughness, as follows.

$$
G_{q}\left(n_{1}, n_{2}\right)=\frac{4 \pi \alpha \rho^{2}}{\left[\alpha^{2}+4 \pi^{2}\left(n_{1}^{2}+n_{2}^{2}\right)\right]^{3 / 2}}
$$

where, $n_{1}$ is spatial frequency with $X$-axis in $m^{-1}, n_{2}$ is spatial frequency with $Y$-axis in $m^{-1}$ and $G_{q}\left(n_{1}, n_{2}\right)$ is PSD of 2-D road roughness with spatial frequency in $m^{3}$.

According to [13], Fourier transform and PSD of 2-D road roughness can be expressed as Equations (7) and (8).

$$
\begin{gathered}
H\left(f_{x}, f_{y}\right)=\lim _{l_{x}, l_{y} \rightarrow \infty} \int_{-l_{x}}^{l_{x}} \int_{l_{y}}^{l_{y}} h(x, y) e^{-j 2 \pi\left(x f_{x}+y f_{y}\right)} d x d y \\
G\left(f_{x}, f_{y}\right)=\lim _{l_{x}, l_{y} \rightarrow \infty} \frac{1}{4 l_{x} l_{y}}\left|H\left(f_{x}, f_{y}\right)\right|^{2}
\end{gathered}
$$

where, $f_{x}$ and $f_{y}$ are spatial frequencies with $X$-axis and $Y$-axis in $m^{-1}$ respectively, $l_{x}$ and $l_{y}$ are surface road lengths; $n_{2}$ is spatial frequency with $Y$-axis in $m^{-1}, h(x, y)$ is 3-D road roughness in $m, G\left(f_{x}, f_{y}\right)$ is PSD of 2-D road roughness for spatial frequency in $m^{3}$, and $H\left(f_{x}, f_{y}\right)$ is Fourier transform of $h(x, y)$.

Due to boundary of the actual road [10], Equations (7) and (8) can be expressed as Equations (9) and (10). 


$$
\begin{gathered}
H\left(f_{p}, f_{q}\right)=\Delta x \Delta y \sum_{m=0}^{M-1} \sum_{n=0}^{N-1} h(m \Delta x, n \Delta y) e^{-j 2 \pi\left(\frac{p}{M} m+\frac{q}{N} n\right)} \\
G\left(f_{p}, f_{q}\right)=\frac{\Delta x \Delta y}{M N}\left|F\left(f_{p}, f_{q}\right)\right|^{2}
\end{gathered}
$$

In addition,

$$
\begin{aligned}
f_{p} & =\frac{p}{M \Delta x} ; p=0,1,2, \cdots, M-1 \\
f_{q} & =\frac{q}{N \Delta x} ; q=0,1,2, \cdots, N-1
\end{aligned}
$$

where, $M$ and $N$ are sampling numbers, $\Delta x$ and $\Delta y$ are sample intervals, $f_{p}$ and $f_{q}$ are discrete spatial frequencies in $m^{-1}$ and $F\left(f_{p}, f_{q}\right)$ is Fourier transform of $h(m \Delta x, n \Delta y)$.

With assumption of stationary random process, road defined in Equation (12) can be computed according to Equation (10) as follows.

$$
F\left(f_{p}, f_{q}\right)=\left|F\left(f_{p}, f_{q}\right)\right| e^{\varphi\left(f_{p}, f_{q}\right)}
$$

where $\phi(f, f)$ is phase angle of $F\left(f_{p}, f_{q}\right)$.

Based on properties of 2-D Fourier transform, function $H(p, q)$, i.e., the Fourier transform of $h(m$, $n)$, may be satisfied by Equation (13).

$$
\begin{gathered}
H(1, N+1-n)=\operatorname{conj}[H(1, n)] ; \\
H(M+1-n, 1)=\operatorname{conj}[H(m, 1)] ; \\
H(M / 2, N+1-n)=\operatorname{conj}[H(M / 2, n)] ; \\
H(M+1-m, N / 2)=\operatorname{conj}[H(m, N / 2)] ; \\
H(M+1-m, N+1-n)=\operatorname{conj}[H(m, n)] ;
\end{gathered}
$$

where conj represents the conjugate; $m=1,2, . ., M / 2-1 ; n=1,2, \ldots, N / 2-1$.

Based on the above analysis, 3-D road roughness can be expressed by Equation (14).

$$
h(m, n)=\frac{1}{M N} \sum_{p=1}^{M-1} \sum_{q=1}^{N-1} F\left(f_{p}, f_{q}\right) e^{j 2 \pi\left(\frac{p}{M} m+\frac{q}{N} n\right)}
$$

Following the analysis presented above, 3-D road roughness for level ISO- $A$ and ISO- $C$ cases are obtained. For instance, analysis is carried out considering level ISO- $A$ excitation (at a velocity of $80 \mathrm{~km} / \mathrm{h}$ ). Results are shown in Figure 2.

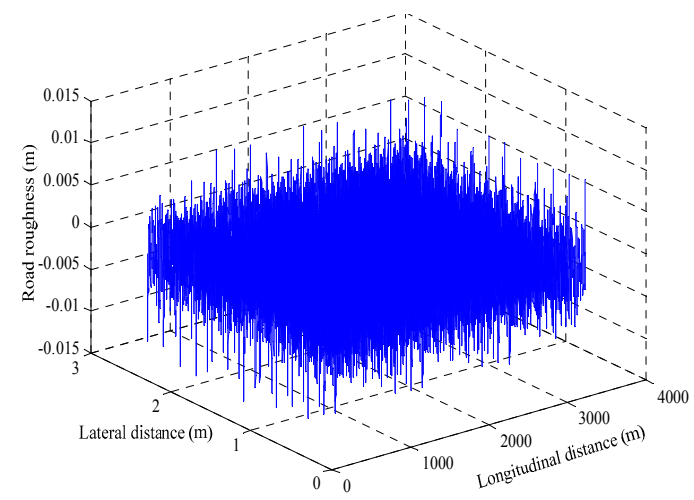

Figure 2. 3-D road roughness for Level ISO- $A$ (at a velocity of $80 \mathrm{~km} / \mathrm{h}$ ). 


\subsubsection{Steering Working Condition}

Movement trace of the vehicle is typically not straight under various steering conditions. As a result, PSD of road roughness while steering should also satisfy its statistical features. Based on the work presented in [14], a triangular mesh method is used for analysis.

Road surface mode is considered to be a triangle grid space similar to the 3-D model shown in Figure 3. Adjacent points $A, C, D$ and $A, B, C$ in the 3-D model can form two triangular planes. When radius $R$ and sampling interval $\Delta l$ are known, coordinates of sampling point $E$ can be located in the plane of triangle $A C D$. Then, road roughness at point $E$ can be obtained by computing road roughness at points $A, B, D$. Following the procedure discussed above, road roughness of other points can be obtained as discussed in [14] and can be validated.

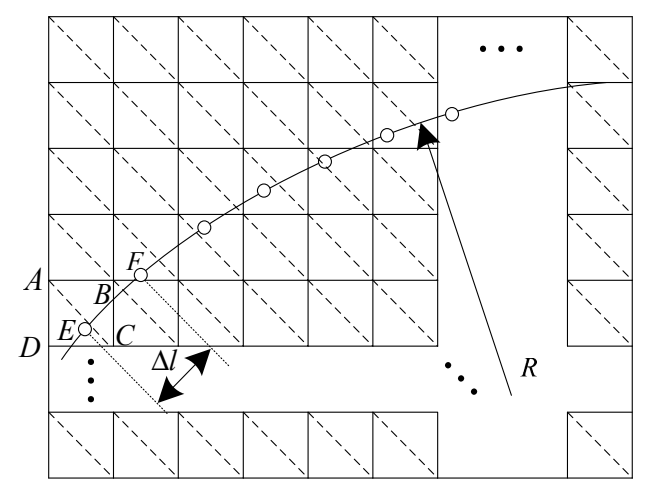

Figure 3. Sampling of elevation about steering track road roughness.

\section{Rollover Index}

A common method of defining rollover index (RI) is based on the difference in vertical tire loads between left and right sides of the vehicle [15].

$$
\mathrm{RI}=\frac{F_{z r}-F_{z l}}{F_{z r}+F_{z l}} ;-1 \leq \mathrm{RI} \leq 1
$$

where $F_{z l}$ and $F_{z r}$ are vertical tire forces on left and right side tires of the vehicle, respectively. When RI is equal to 1 or -1 , right or left wheel lifts off.

Forces on the tire $F_{z l}$ and $F_{z r}$ cannot be directly measured. To obtain RI in this situation, a 4-DOF vehicle model was developed as shown in Figure 4, A new RI* can be derived from Equation (15) [16].

$$
\begin{aligned}
\mathrm{RI}^{*}=\frac{F_{z r}-F_{z l}}{F_{z r}+F_{z l}} & =\frac{l_{s}}{l_{w}} \frac{k_{s} l_{s} \sin \phi+c l_{s} \dot{\phi} \cos \phi+k_{s}\left(z_{u 1}-z_{u 2}\right)+c\left(\dot{z}_{u 1}-\dot{z}_{u 2}\right)}{\left(m g-2 k_{s} z_{s}-2 c \dot{z}_{s}+k_{s}\left(z_{u 1}+z_{u 2}\right)+c\left(\dot{z}_{u 1}+\dot{z}_{u 2}\right)\right)} \\
& +\frac{2}{l_{w}} \frac{F_{l a t} h_{l a t}}{\left(m g-2 k_{s} z_{s}-2 c \dot{z}_{s}+k_{s}\left(z_{u 1}+z_{u 2}\right)+c\left(\dot{z}_{u 1}+\dot{z}_{u 2}\right)\right)}
\end{aligned}
$$

where $h_{r}$ is distance between C.G. height and roll center; $\varphi$ represents roll angle; $a_{y}$ represents lateral acceleration; $F_{\text {lat }}$ is lateral force; $h_{\text {lat }}$ is distance from input lateral force to roll center; $z_{r l}$ and $z_{r r}$ are left and right road excitation, respectively. As shown in Figure $4, l_{s}$ is body distance between left suspension and right suspension, i.e., $l_{s}$ is distance of a hinged between suspension and vehicle body; $l_{w}$ is track width; $k_{s}$ is suspension stiffness; $z_{u 1}$ and $z_{u 2}$ represent left and right unsprung mass positions, respectively; $c$ is suspension damping; $m$ is equal to sum of $m_{s}$ and $m_{u}, m_{s}$ and $m_{u}$ are the sprung mass and unsprung mass of the vehicle, respectively. 


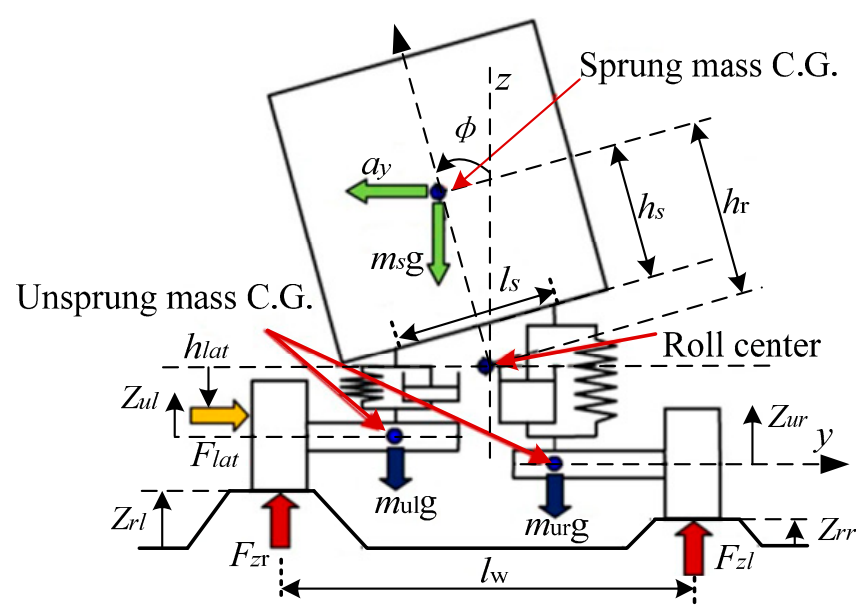

Figure 4. Roll behavior of vehicle system.

\section{Vehicle Dynamics Model}

In this section, a half-car and a full-car dynamics models are utilized to analyze roll behavior of vehicle system.

\subsection{Half-Car Dynamics Model}

In practical scenarios, the real vehicle influence of wheel base or track on vehicle system can be neglected under some special conditions. In this study, the effect of the vehicle's unsprung mass on roll dynamics is not neglected [15]. To obtain a functional relationship between road excitation and roll dynamics model, a half-car model is first presented, as shown in Figure 5. This model is a combination of a traditional 2-DOF bicycle model and a 4-DOF roll dynamics model used to describe yaw, lateral motion, and roll motion.

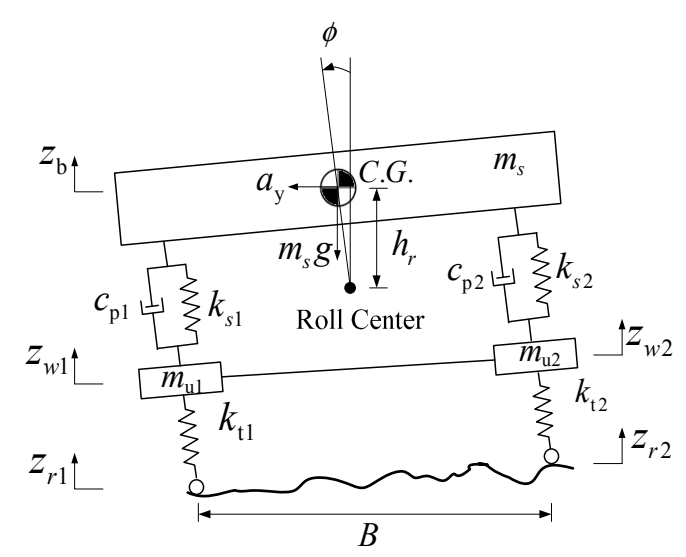

Figure 5. Half-car roll dynamics model.

It should be noted that left and right steering angles in general would be approximately equal [17]. Symbols used in Figure 5 are listed in Table 2. Parameters in Table 2 are from the CARSIM ${ }^{\circledR}$ (E-Class, SUV). Here, lateral load transfer is considered for every wheel.

The half-car dynamics model is constructed based on the following assumptions $[17,18]$.

1. Distance between two axles compared to turning radius was relative small, and steering wheel angle satisfies the following relationship: $\sin \delta_{f}=\delta_{f}, \cos \delta_{f}=1$.

2. Longitudinal effect of road profile was ignored. 
3. There is no slip between the tires and road surface, and influence of ground longitudinal force on cornering characteristics of the tires was not considered.

4. The effect of the steering system was excluded, and front wheel angle was directly used as input.

5. The effect of air force was ignored.

6. Suspension elastic deformation steering and change of steering wheel alignment parameters were ignored.

7. The influence of bearing-free gap and lubricant membrane was ignored, and the bearing was taken as an equivalent spring-damper system in the vertical direction.

Table 2. Description of symbols for 6-DOF half-car dynamics model.

\begin{tabular}{ccc}
\hline Vehicle Model Parameters & Symbol & Unit \\
\hline Lateral acceleration & $a_{y}$ & $\mathrm{~m} / \mathrm{s}^{2}$ \\
Roll angle of sprung mass & $\varphi$ & $\mathrm{deg}\left(^{\circ}\right)$ \\
Front tire cornering stiffness & $C_{f}$ & $\mathrm{~N} /{ }^{\circ}$ \\
Rear tire cornering stiffness & $C_{r}$ & $\mathrm{~N} /{ }^{\circ}$ \\
Total mass of the vehicle & $M_{1}$ & $\mathrm{~kg}$ \\
Sprung mass of vehicle body & $m_{s}$ & $\mathrm{~kg}$ \\
Unsprung mass of vehicle left side & $m_{u 1}$ & $\mathrm{~kg}$ \\
Unsprung mass of vehicle right side & $m_{u 2}$ & $\mathrm{~kg}$ \\
Suspension stiffness of left side & $k_{s 1}$ & $\mathrm{~N} / \mathrm{m}$ \\
Suspension stiffness of right side & $k_{s 2}$ & $\mathrm{~N} / \mathrm{m}$ \\
Suspension damping coefficient of left side & $c_{p 1}$ & $\mathrm{Ns} / \mathrm{m}$ \\
Suspension damping coefficient of right side & $c_{p 2}$ & $\mathrm{Ns} / \mathrm{m}$ \\
Tire stiffness of left side & $k_{t 1}$ & $\mathrm{~N} / \mathrm{m}$ \\
Tire stiffness of right side & $k_{t 2}$ & $\mathrm{~N} / \mathrm{m}$ \\
Sprung mass displacement of vehicle body & $z_{b}$ & $\mathrm{~m}$ \\
Unsprung mass displacement of left side & $z_{w 1}$ & $\mathrm{~m}$ \\
Unsprung mass displacement of right side & $z_{w 2}$ & $\mathrm{~m}$ \\
Road profile of left side & $z_{r 1}$ & $\mathrm{~m}$ \\
Road profile of right side & $z_{r 2}$ & $\mathrm{~m}$ \\
Track width & $B$ & $\mathrm{~m}$ \\
Ristance between roll center to C.G. of sprung mass & $h_{r}$ & $\mathrm{~m}$ \\
Roll damping coefficient & $C_{\text {roll }}$ & $\mathrm{Ns} / \mathrm{m}$ \\
Roll stiffness coefficient & $K_{\text {roll }}$ & $\mathrm{N} / \mathrm{m}$ \\
\hline
\end{tabular}

\subsubsection{Tire Modelling}

The Magic Formula (MF) Tire Model established by Pacejka [17] is utilized here. MF is a commonly used nonlinear tire model which has the general form shown below:

$$
\begin{gathered}
y=D \sin [C \arctan \{B x-E(B x-\arctan (B x))\}] \\
Y(X)=\quad y(x)+S_{\mathrm{V}} \\
x=X+S_{\mathrm{H}}
\end{gathered}
$$

where $X$ is input state, which represents slip ratio or slip angle; $Y$ is output state and represents longitudinal force, lateral force or aligning torque. Factors $C, D, B$ and $E$ are usually derived from experiments. $D$ is peak value of the curve; $C$ determines shape of the obtained curve; $B$ represents stiffness value of the curve; $E$ represents curvature of the curve; $S_{H}$ and $S_{v}$ are offset values of input and output states.

In combined slip conditions, lateral force will decrease due to longitudinal slip, and the longitudinal force will decrease due to lateral slip. Force and moments in this situation are obtained by multiplication of some weighing parameters with pure slip characteristics. However, tire longitudinal slip is defined to zero under constant vehicle longitudinal velocity. Various scaling factors are available 
in the MF model to check influence of changing tire properties without using real MF coefficients [18]. The details are stated in [17].

For known empirical formula, tire models for wheels of the vehicle can be obtained as shown in Figure 6.

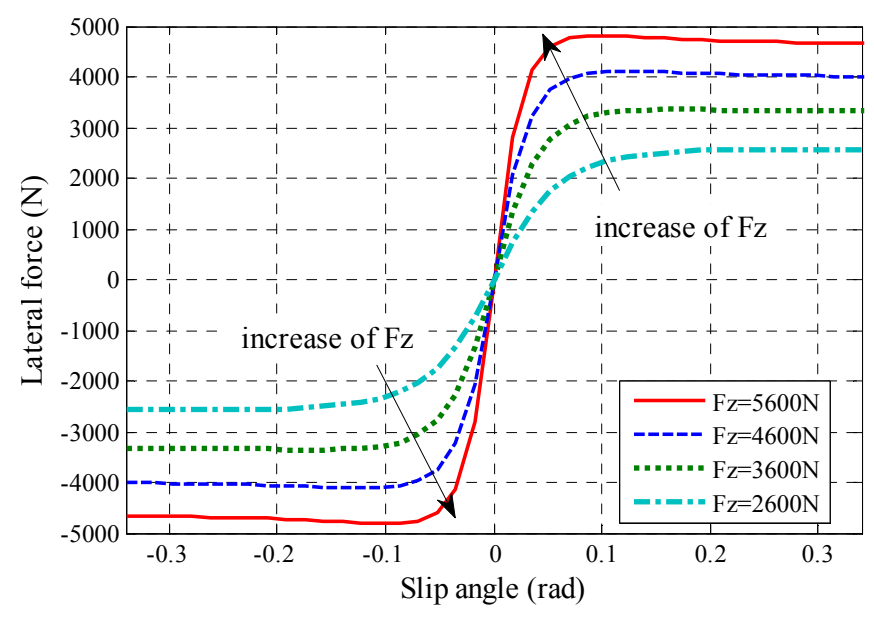

Figure 6. Influence of vertical force on tire lateral force.

\subsubsection{Lateral Acceleration Calculation}

Based on a traditional 2-DOF bicycle model [17], the dynamics equations can be expressed as follows:

$$
\begin{aligned}
& M_{1} a_{y}-m_{b} h_{r} \ddot{\phi}-\left(F_{y f}+F_{y r}\right)=0 \\
& I_{z} \dot{\gamma}+I_{z x} \ddot{\phi}-I_{x y} \ddot{\phi}^{2}-\left(a F_{y f}-b F_{y r}+M\right)=0
\end{aligned}
$$

where $I_{z}, I_{x y}$ and $I_{z x}$ are moment of inertia along $Z$ axis, $X-Y$ axis and $Z-X$ axis, respectively. $M$ is yaw moment, $F_{y f}$ and $F_{y r}$ represent lateral force of front wheel and rear wheel. Other parameters are shown in Table 2. More details are stated in $[17,18]$.

To solve for the desired lateral acceleration, according to vehicle theory [17], front tire slip angle $\alpha_{f}$ and rear tire slip angle $\alpha_{f}$ can be calculated as follows:

$$
\left\{\begin{aligned}
\alpha_{f} & =\frac{v_{y}}{v_{x}}+\frac{a \gamma}{v_{x}}-\delta_{f} \\
\alpha_{r} & =\frac{v_{y}}{v_{x}}-\frac{b \gamma}{v_{x}}
\end{aligned}\right.
$$

where $v_{x}$ and $v_{y}$ are longitudinal and lateral velocity, respectively. a and $\mathrm{b}$ are distance from C.G. to front axle and rear axle. $\delta_{f}$ is front steering angle. $\gamma$ represents yaw rate.

In this paper, acceleration in $Y$-direction and yaw angle were obtained as follows:

$$
\begin{gathered}
\dot{v}_{y}=\frac{-2\left(C_{f}+C_{r}\right) v_{y}-2\left(a C_{f}-b C_{r}\right) \gamma}{M_{1} \cdot v_{x}}+\frac{2 C_{f} \cdot \delta_{f}}{M_{1}}-v_{x} \cdot \gamma \\
\dot{\gamma}=\frac{-2\left(a C_{f}-b C_{r}\right) v_{y}-2\left(a^{2} C_{f}+b^{2} C_{r}\right) \gamma}{I_{z} \cdot v_{x}}+\frac{2 a \cdot C_{f} \cdot \delta_{f}}{I_{z}}
\end{gathered}
$$

Desired lateral acceleration for a driver's steering input is expressed as follows:

$$
a_{y}=\dot{v}_{y}+v_{x} \gamma=\frac{-2\left(C_{f}+C_{r}\right) v_{y}-2\left(a C_{f}-b C_{r}\right) \gamma}{M_{1} \cdot v_{x}}+\frac{2 C_{f} \cdot \delta_{f}}{M_{1}}
$$


Remark. Tire cornering stiffness is calculated using MF in Section 4.1.1, and other parameters can be obtained using CARSIM ${ }^{\circledR}$ simulation (version 8.02; Publisher: Mechanical Simulation Corporation, Detroit, MI, USA, 1996-2010).

\subsubsection{4-DOF Roll Dynamics Model}

As shown in Figure 5, 4-DOF considered in this model are vertical translation of the sprung mass denoted by $z_{b}$, roll motion of sprung mass denoted by $\varphi$ and vertical translation of left and right unsprung mass denoted by $z_{w 1}$ and $z_{w 2}$, respectively.

Vertical force balance on sprung mass and two unsprung masses can be expressed as Equations (24)-(26).

$$
\begin{gathered}
m_{s} \ddot{z}_{b}=F_{s 1}+F_{s 2} \\
m_{u 1} \ddot{z}_{w 1}=-F_{s 1}-k_{t 1}\left(z_{w 1}-z_{r 1}\right) \\
m_{u 2} \ddot{z}_{w 2}=-F_{s 2}-k_{t 2}\left(z_{w 2}-z_{r 2}\right)
\end{gathered}
$$

where $F_{s 1}$ and $F_{s 2}$ are forces on both sides (left and right) of the suspension.

Roll dynamics of sprung mass are developed as follows.

$$
\left(I_{x}+m_{s} h_{r}\right) \ddot{\phi}=m_{s}\left(a_{y} \cos \phi+g \sin \phi\right) h_{r}+\frac{B}{2}\left(F_{s 1}-F_{s 2}\right)
$$

where $I_{x}$ is moment of inertia along $X$ axis; $a_{y}$ is lateral acceleration; $g$ is gravitational acceleration; Calculation is shown in Section 4.1.2.

Dynamics suspension forces are given in Equations (28) and (29).

$$
\begin{aligned}
& F_{s 1}=-k_{s 1}\left(z_{b}-z_{w 1}-\frac{B \sin \phi}{2}\right)-c_{p 1}\left(\dot{z}_{b}-\dot{z}_{w 1}-\frac{B \dot{\phi} \cos \phi}{2}\right) \\
& F_{s 2}=-k_{s 2}\left(z_{b}-z_{w 2}+\frac{B \sin \phi}{2}\right)-c_{p 2}\left(\dot{z}_{b}-\dot{z}_{w 2}+\frac{B \dot{\phi} \cos \phi}{2}\right)
\end{aligned}
$$

Dynamics tire forces are given by Equations (30) and (31).

$$
\begin{aligned}
& F_{t l}=-k_{t 1}\left(z_{w 1}-z_{r 1}\right) \\
& F_{t r}=-k_{t 2}\left(z_{w 2}-z_{r 2}\right)
\end{aligned}
$$

where $F_{t l}$ and $F_{t r}$ are forces on left and right sides of the tire, respectively.

Assuming $c_{p 1}=c_{p 2}=c_{p}$ and $k_{s 1}=k_{s 2}=k_{s}$, and substituting Equations (28) and (29) into Equation (27), overall equations of motion are obtained as follows.

$$
\begin{aligned}
m_{s} \ddot{z}_{s}= & -k_{s 2}\left(z_{b}-z_{w 2}+\frac{B \sin \phi}{2}\right)-c_{p 2}\left(\dot{z}_{b}-\dot{z}_{w 2}+\frac{B \dot{\phi} \cos \phi}{2}\right) \\
& -k_{s 1}\left(z_{b}-z_{w 2}-\frac{B \sin \phi}{2}\right)-c_{p 1}\left(\dot{z}_{b}-\dot{z}_{w 1}-\frac{B \dot{\phi} \cos \phi}{2}\right) \\
m_{w 1} \ddot{z}_{w 1}= & k_{s 1}\left(z_{b}-z_{w 2}-\frac{B \sin \phi}{2}\right)+c_{p 1}\left(\dot{z}_{b}-\dot{z}_{w 1}-\frac{B \dot{\phi} \cos \phi}{2}\right) \\
& -k_{t 1}\left(z_{w 1}-z_{r 1}\right) \\
m_{w 2} \ddot{z}_{w 2}= & -k_{s 2}\left(z_{b}-z_{w 2}+\frac{B \sin \phi}{2}\right)-c_{p 2}\left(\dot{z}_{b}-\dot{z}_{w 2}+\frac{B \dot{\phi} \cos \phi}{2}\right) \\
& -k_{t 2}\left(z_{w 2}-z_{r 2}\right)
\end{aligned}
$$




$$
\begin{aligned}
\left(I_{x}+m_{s} h_{R}\right) \ddot{\phi}= & m_{s}\left(a_{y} \cos \phi+g \sin \phi\right) h_{R}-\frac{k_{s} B^{2}}{2} \sin \phi \\
& -\frac{c_{p} B^{2}}{2} \dot{\phi} \cos \phi+\frac{k_{s} B}{2}\left(z_{w}-z_{r}\right)+\frac{c_{p} B}{2}\left(\dot{z}_{w}-\dot{z}_{r}\right)
\end{aligned}
$$

where $\ddot{z}_{u 1}$ and $\ddot{z}_{u 2}$ are acceleration on left and right sides of the suspension, respectively; $\dot{z}_{w}-\dot{z}_{r}$ is rattle space velocity between velocities of unsprung mass and road profile height.

Total tire forces on the ground include both static forces due to weight and dynamic force. Including both static and dynamic forces, total tire forces on the ground are given by

$$
\begin{aligned}
& F_{z l}=\frac{m_{s}}{2} g+m_{u 1} g-k_{t 1}\left(z_{w 1}-z_{r 1}\right) \\
& F_{z r}=\frac{m_{s}}{2} g+m_{u 22} g-k_{t 2}\left(z_{w 2}-z_{r 2}\right)
\end{aligned}
$$

Since vertical forces $F_{z l}$ and $F_{z r}$ are equal to vertical forces on the tire, i.e., $F_{t l}$ and $F_{t r}$, Equation (16) can also be expressed as follows.

$$
\mathrm{RI}_{\text {half }}=\frac{m_{u 2} \ddot{z}_{w 2}+F_{s 2}+m_{u 2} g-m_{u 1} \ddot{z}_{w 1}-F_{s 1}-m_{u 1} g}{m_{u 2} \ddot{z}_{w 2}+F_{s 2}+m_{u 2} g+m_{u 1} \ddot{z}_{w 1}+F_{s 1}+m_{u 1} g}
$$

Considering $m_{u 1}=m_{u 2}=m_{u}$, Equation (34) can be further simplified. By substituting Equations (31)-(34) into Equation (38), simplified $\mathrm{RI}_{\text {half }}$ equation can be obtained as follows [16].

$$
\begin{aligned}
\mathrm{RI}_{h a l f}= & \frac{m_{u}\left(\ddot{z}_{w 2}-\ddot{z}_{w 1}\right)-\frac{2}{B^{2}}\left(I_{x}+m_{s} h_{r}{ }^{2}\right)\left(\ddot{z}_{b 1}-\ddot{z}_{b 2}\right)}{m_{u}\left(\ddot{z}_{w 2}+\ddot{z}_{w 1}\right)+m_{s} \ddot{z}_{b}+\left(2 m_{u}+m_{s}\right) g} \\
& +\frac{\frac{2}{B^{2}} m_{s} a_{y} h_{r} \cos \phi+\frac{2}{B^{2}} m_{s} h_{r} \sin \phi}{m_{u}\left(\ddot{z}_{w 2}+\ddot{z}_{w 1}\right)+m_{s} \ddot{z}_{b}+\left(2 m_{u}+m_{s}\right) g}
\end{aligned}
$$

In addition,

$$
\begin{aligned}
& \ddot{z}_{b 1}=\ddot{z}_{b} \cos \phi-\frac{B}{2} \ddot{\phi}+a_{y} \sin \phi+g \cos \phi \\
& \ddot{z}_{b 2}=\ddot{z}_{b} \cos \phi+\frac{B}{2} \ddot{\phi}+a_{y} \sin \phi+g \cos \phi
\end{aligned}
$$

where, $\ddot{z}_{b 1}$ represents acceleration of left suspension stiff body points attached to the vehicle body, $\ddot{z}_{b 2}$ represents acceleration of right suspension stiff body points attached to the vehicle body, $\left(\ddot{z}_{b 1}-\ddot{z}_{b 2}\right)$ is difference sprung mass acceleration.

\subsection{Full-Car Dynamics Model}

Due to the complexity and uncertainty of practical vehicle driving and road conditions, front and rear coherence properties of vehicle and road can not be ignored. Steering wheel angle does not satisfy following relationship when compared with sharp turning: $\sin \delta_{f l}=\delta_{f l}, \cos \delta_{f l}=1$.

To further adapt vehicle driving and road conditions, compared to a 6-DOF half-car model, a full-car dynamics model with 9-DOF was developed based on the above assumptions [17,18]. Vertical and lateral coupling dynamics of the vehicle were considered simultaneously as shown in Figure 7 . The 9-DOF included three degrees of freedom for vertical, pitch, and roll movement of the vehicle body, 4-DOF for vertical movement of unsprung masses, and 2-DOF for lateral and yawing movement of the vehicle. Descriptions of the symbols used in Figure 7 are listed in Table 3. Parameters in Table 3 also come from CARSIM ${ }^{\circledR}$ (E-Class, SUV; version 8.02; Publisher: Mechanical Simulation Corporation, Detroit, MI, USA, 1996-2010). 


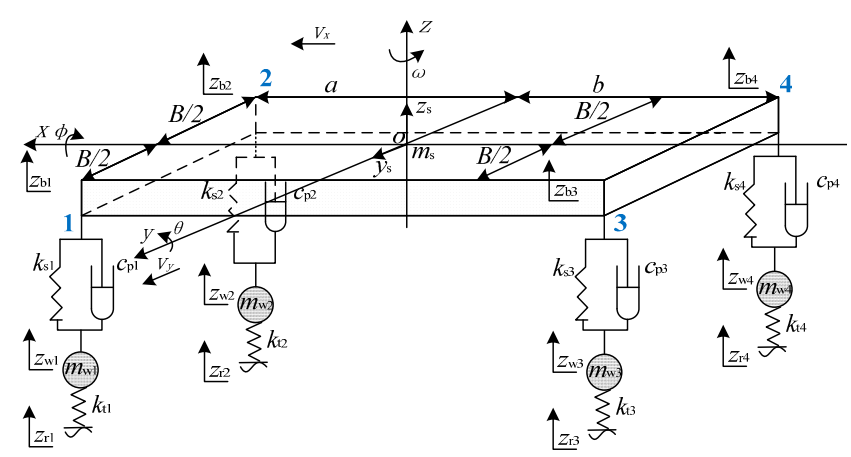

(a)

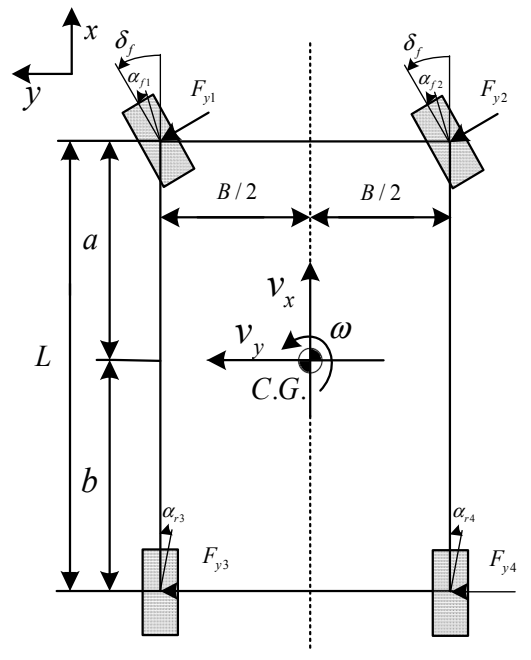

(b)

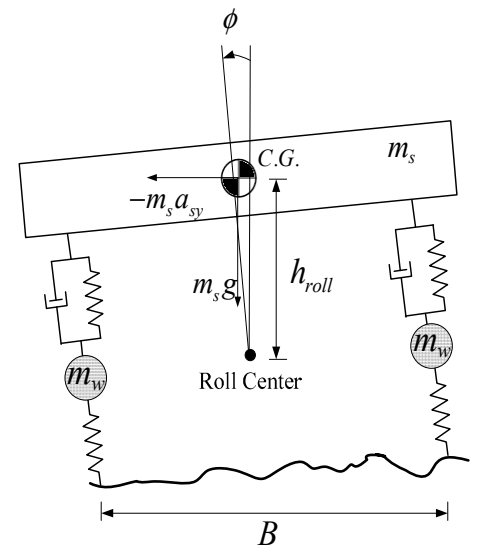

(c)

Figure 7. 9-DOF vehicle dynamics model. (a) Full-car dynamics model. (b) Lateral dynamics model. (c) Roll dynamics model.

Table 3. Description of symbols used for 9-DOF full-car dynamics model.

\begin{tabular}{ccc}
\hline Vehicle Model Parameters & Symbol & Unit \\
\hline Steering angle of front left side & $\delta_{f l}$ & $\operatorname{deg}\left(^{\circ}\right)$ \\
Steering angle of front right side & $\delta_{f r}$ & $\operatorname{deg}\left(^{\circ}\right)$ \\
Rear tire slip angle & $\alpha_{r}$ & $\operatorname{deg}\left(^{\circ}\right)$ \\
Displacement of the front/rear axle & $B$ & $\mathrm{~m}$ \\
Longitudinal displacement of chassis & $x$ & $\mathrm{~m}$ \\
Lateral displacement of chassis & $y$ & $\mathrm{~m}$ \\
Lateral velocity of sprung mass C.G. & $V_{y}$ & $\mathrm{~m} / \mathrm{s}$ \\
Longitudinal velocity of sprung mass C.G. & $V_{x}$ & $\mathrm{~m} / \mathrm{s}$ \\
Suspension stiffness of left front side & $k_{s 1}$ & $\mathrm{~N} / \mathrm{m}$ \\
Suspension stiffness of right front side & $k_{s 2}$ & $\mathrm{~N} / \mathrm{m}$ \\
Suspension stiffness of left rear side & $k_{s 3}$ & $\mathrm{~N} / \mathrm{m}$ \\
Suspension stiffness of right rear side & $k_{s 4}$ & $\mathrm{~N} / \mathrm{m}$ \\
Suspension damping coefficient of left front side & $c_{p 1}$ & $\mathrm{Ns} / \mathrm{m}$ \\
Suspension damping coefficient of right front side & $c_{p 2}$ & $\mathrm{Ns} / \mathrm{m}$ \\
Suspension damping coefficient of left rear side & $c_{p 3}$ & $\mathrm{Ns} / \mathrm{m}$ \\
Suspension damping coefficient of right rear side & $c_{p 4}$ & $\mathrm{Ns} / \mathrm{m}$ \\
Tire stiffness of left front side & $k_{t 1}$ & $\mathrm{~N} / \mathrm{m}$ \\
Tire stiffness of right front side & $k_{t 2}$ & $\mathrm{~N} / \mathrm{m}$ \\
Tire stiffness of left rear side & $k_{t 3}$ & $\mathrm{~N} / \mathrm{m}$ \\
Tire stiffness of right rear side & $k_{t 4}$ & $\mathrm{~N} / \mathrm{m}$
\end{tabular}


Table 3. Cont.

\begin{tabular}{ccc}
\hline Vehicle Model Parameters & Symbol & Unit \\
\hline Unsprung mass vertical displacement of left front side & $z_{w 1}$ & $\mathrm{~m}$ \\
Unsprung mass vertical displacement of right front side & $z_{w 2}$ & $\mathrm{~m}$ \\
Unsprung mass vertical displacement of left rear side & $z_{w 3}$ & $\mathrm{~m}$ \\
Unsprung mass vertical displacement of right rear side & $z_{w 4}$ & $\mathrm{~m}$ \\
Sprung mass of vehicle body & $m_{s}$ & $\mathrm{~kg}$ \\
Unsprung mass of vehicle left front side & $m_{w 1}$ & $\mathrm{~kg}$ \\
Unsprung mass of vehicle right front side & $m_{w 2}$ & $\mathrm{~kg}$ \\
Unsprung mass of vehicle left rear side & $m_{w 3}$ & $\mathrm{~kg}$ \\
Unsprung mass of vehicle right rear side & $m_{w 4}$ & $\mathrm{~kg}$ \\
Road profile of left front side & $z_{r 1}$ & $\mathrm{~m}$ \\
Road profile of right front side & $z_{r 2}$ & $\mathrm{~m}$ \\
Road profile of left rear side & $z_{r 3}$ & $\mathrm{~m}$ \\
Road profile of right rear side & $z_{r 4}$ & $\mathrm{~m}$ \\
Distance between roll center to C.G. of sprung mass & $h_{\text {roll }}$ & $\mathrm{m}$ \\
Roll angle of sprung mass around $x$-axis of $S_{v}$ & $\varphi_{1}$ & $\mathrm{deg}\left({ }^{\circ}\right)$ \\
Pitch angle of sprung mass around $y$-axis of $S_{v}$ & $\theta$ & $\mathrm{deg}\left(^{\circ}\right)$ \\
Yaw rate of sprung mass around $z$-axis of $S_{v}$ & $\omega$ & $\mathrm{deg} / \mathrm{s}\left(^{\circ} / \mathrm{s}\right)$ \\
\hline
\end{tabular}

\subsubsection{Kinematics of Vehicle System}

In this section, the major coordinate system is established, i.e., $S_{G}$ is the earth-fixed inertial reference coordinate frame and $S_{v}$ is the vehicle fixed non-inertial reference coordinate frame. Rotating angular velocity of $S_{v}$ is $w_{v}$, and Translating velocity of $S_{v}$ is $v_{v}$. The corresponding equations of the 9-DOF model are stated as follows. More details can be found in $[15,17]$.

Translation of Sprung Mass C.G.

Position of C.G. of sprung mass in the reference coordinate frame $S_{v}$ can be expressed as:

$$
\vec{l}_{\text {os }}=R_{y}(\theta) R_{x}(\phi)\left[\begin{array}{c}
0 \\
0 \\
-h_{\text {roll }}
\end{array}\right]+\left[\begin{array}{c}
0 \\
0 \\
z_{b}
\end{array}\right]=\left[\begin{array}{c}
-h_{\text {roll }} \cos \phi \sin \theta \\
h_{\text {roll }} \sin \theta \\
-h_{\text {roll }} \cos \phi \sin \theta+z_{b}
\end{array}\right]
$$

And,

$$
R_{y}(\theta)=\left[\begin{array}{ccc}
\cos \theta & 0 & \sin \theta \\
0 & 1 & 0 \\
-\sin \theta & 0 & \cos \theta
\end{array}\right] ; R_{x}(\phi)=\left[\begin{array}{ccc}
1 & 0 & 0 \\
0 & \cos \phi & -\sin \phi \\
0 & \sin \phi & \cos \phi
\end{array}\right]
$$

Then,

$$
\left(\frac{d}{d t}\right)_{G} \vec{l}_{o s}=\left(\frac{d}{d t}\right)_{v} \vec{l}_{o s}+\boldsymbol{w}_{v} \times \vec{l}_{o s}
$$

where ' $X$ ' represents the cross-product operator, and $w_{v}=\left[\begin{array}{lll}0 & 0 & w\end{array}\right]^{\mathrm{T}}$.

Velocity of sprung mass C.G. with respect to $S_{\mathrm{G}}$ is denoted as the sum of translational $v_{v}$ of the vehicle reference coordinate frame $S_{v}$ and the time derivative of position $\vec{l}_{o s}$.

$$
\boldsymbol{v}_{s}=\boldsymbol{v}_{v}+\left(\frac{d}{d t}\right)_{G}=\boldsymbol{v}_{v}+\left(\frac{d}{d t}\right)_{v} \vec{l}_{o s}+\boldsymbol{w}_{v} \times \vec{l}_{o s}=\boldsymbol{v}_{v}+\dot{\vec{l}}_{o s}+\boldsymbol{w}_{v} \times \vec{l}_{o s}
$$

where " $\times$ " represents the cross-product operator, and $\boldsymbol{v}_{v}=\left[\begin{array}{lll}V_{x} & V_{y} & 0\end{array}\right]^{\mathrm{T}}$.

The acceleration of sprung mass C.G. with respect to $S_{G}$ is calculated as:

$$
\boldsymbol{a}_{s}=\left(\frac{d}{d t}\right)_{G} \boldsymbol{v}_{s}=+\left(\frac{d}{d t}\right)_{v} \boldsymbol{v}_{v}+\boldsymbol{w}_{v} \times \boldsymbol{v}_{v}=\dot{\boldsymbol{v}}_{v}+\boldsymbol{w}_{v} \times \boldsymbol{v}_{v}
$$


Translation of Unsprung Mass C.G.

As mentioned in Section 4.2.1, position of unsprung mass C.G. in the reference coordinate frame $S_{v}$ can be expressed as:

$$
\vec{l}_{w 1}=\left[\begin{array}{c}
a \\
-\frac{B}{2} \\
z_{w 1}-h_{w 1}
\end{array}\right] ; \vec{l}_{w 2}=\left[\begin{array}{c}
a \\
\frac{B}{2} \\
z_{w 2}-h_{w 2}
\end{array}\right] ; \vec{l}_{w 3}=\left[\begin{array}{c}
-b \\
-\frac{B}{2} \\
z_{w 3}-h_{w 3}
\end{array}\right] ; \vec{l}_{w 4}=\left[\begin{array}{c}
-b \\
-\frac{B}{2} \\
z_{w 4}-h_{w 4}
\end{array}\right]
$$

where, we denote that 1 as left-front of vehicle, 2 as right-front of vehicle, 3 as left-rear of vehicle and 4 as right-rear of vehicle. Also, $h_{w i}$ represents height of the roll axis above the ground for $i=1,2,3,4$.

Then, corresponding velocities and accelerations of vehicle unsprung mass C.G. with respect to $S_{G}, \boldsymbol{v}_{s i}$ and $\boldsymbol{a}_{s i}, i=1,2,3,4$, can be calculated using Equations (45) and (46).

Rotations of C.G. of Unsprung Mass

Angular momentum $\boldsymbol{D}_{s}$ of the sprung mass can be expressed as:

$$
\boldsymbol{D}_{s}=m_{s} \vec{l}_{o s} \vec{l}_{\text {os }} \times \boldsymbol{v}_{s}+\boldsymbol{I}_{s} \boldsymbol{w}_{s}=\left(\boldsymbol{D}_{C G}\right)_{s}+\left(\boldsymbol{D}_{w}\right)_{s}
$$

where, $\left(\boldsymbol{D}_{C G}\right)_{s}$ is angular momentum of sprung mass C.G. due to motion, $\left(\boldsymbol{D}_{w}\right)_{s}$ is angular momentum of sprung mass C.G. due to rotation, and $w_{s}=[\dot{\phi} \dot{\theta} w]^{\mathrm{T}}$.

Also, angular momentum $\boldsymbol{D}_{w}$ of unsprung mass can be expressed as:

$$
\boldsymbol{D}_{w}=\sum_{i=4}^{4}\left[m_{w i}\left(\boldsymbol{w}_{i} \times \boldsymbol{v}_{i}\right)+\boldsymbol{I}_{w i} \boldsymbol{w}_{v}\right]
$$

Total angular momentum $\boldsymbol{D}$ of vehicle can be expressed as:

$$
\boldsymbol{D}=\boldsymbol{D}_{s}+\boldsymbol{D}_{w}
$$

\subsubsection{Dynamics of Vehicle System}

Based on Newton's law, dynamics equations of the 9-DOF full-car model are as follows.

1. Equation (51) for vehicle body vertical motion

$$
\sum_{i=1}^{4} F_{s i}=-m_{s} \ddot{z}_{s}
$$

where $F_{s i}$ is suspension force. Corresponding equations can be obtained as follows.

$$
\begin{aligned}
& F_{s 1}=-k_{s 1}\left(z_{b 1}-z_{w 1}\right)-c_{p 1}\left(\dot{z}_{b 1}-\dot{z}_{w 1}\right) ; \\
& F_{s 2}=-k_{s 2}\left(z_{b 2}-z_{w 2}\right)-c_{p 2}\left(\dot{z}_{b 2}-\dot{z}_{w 2}\right) ; \\
& F_{s 3}=-k_{s 3}\left(z_{b 3}-z_{w 3}\right)-c_{p 3}\left(\dot{z}_{b 3}-\dot{z}_{w 3}\right) ; \\
& F_{s 4}=-k_{s 4}\left(z_{b 4}-z_{w 4}\right)-c_{p 4}\left(\dot{z}_{b 4}-\dot{z}_{w 4}\right) ;
\end{aligned}
$$

And,

$$
\begin{aligned}
& z_{b 1}=z_{b}+\frac{B}{2} \sin \phi-a \sin \theta ; \\
& z_{b 2}=z_{b}-\frac{B}{2} \sin \phi-a \sin \theta ; \\
& z_{b 3}=z_{b}+\frac{B}{2} \sin \phi+b \sin \theta ; \\
& z_{b 4}=z_{b}-\frac{B}{2} \sin \phi+b \sin \theta ;
\end{aligned}
$$


2. Equation (54) for unsprung mass vertical motion

$$
\begin{aligned}
& m_{w 1} \ddot{z}_{w 1}=-k_{s 1}\left(z_{w 1}-z_{b 1}\right)-c_{p 1}\left(\dot{z}_{w 1}-\dot{z}_{b 1}\right)-k_{t 1}\left(z_{w 1}-z_{r 1}\right) ; \\
& m_{w 22} \ddot{z}_{w 2}=-k_{s 2}\left(z_{w 2}-z_{b 2}\right)-c_{p 2}\left(\dot{z}_{w 2}-\dot{z}_{b 2}\right)-k_{t 2}\left(z_{w 2}-z_{r 2}\right) ; \\
& m_{w 33} \ddot{z}_{w 3}=-k_{s 3}\left(z_{w 3}-z_{b 3}\right)-c_{p 3}\left(\dot{z}_{w 3}-\dot{z}_{b 3}\right)-k_{t 3}\left(z_{w 3}-z_{r 3}\right) ; \\
& m_{w 4} \ddot{z}_{w 4}=-k_{s 4}\left(z_{w 4}-z_{b 4}\right)-c_{p 4}\left(\dot{z}_{w 4}-\dot{z}_{b 4}\right)-k_{t 4}\left(z_{w 4}-z_{r 4}\right) ;
\end{aligned}
$$

3. Equation (55) for vehicle body pitch motion

$$
\sum_{i=1}^{4} M_{y i}=I_{y i} \ddot{\theta}=\left(F_{s 1}+F_{s 2}\right) a-\left(F_{s 3}+F_{s 4}\right) b+m_{s} g h_{\text {roll }} \sin \theta
$$

where $M_{y i}, i=1,2,3,4$ is vehicle roll moment.

4. Equation (56) for vehicle body roll motion

$$
\sum_{i=1}^{4} M_{x i}=I_{x} \ddot{\phi}=\left(F_{s 2}+F_{s 4}\right) \frac{B}{2}-\left(F_{s 1}+F_{s 3}\right) \frac{B}{2}+m_{s} h_{\text {roll }}\left(g \sin \theta+a_{s y}\right)
$$

where $M_{x i}, i=1,2,3,4$ is vehicle roll moment.

5. Equation (57) for vehicle lateral motion

$$
\sum_{i=1}^{4} F_{y i}=m_{s} a_{s y}+\sum_{i=1}^{4} m_{w i} a_{w y i}=\left(F_{y 1}+F_{y 2}\right) \cos \delta_{f}+\left(F_{y 3}+F_{y 4}\right) \cos \delta_{r} ;
$$

where $F_{y i}, i=1,2,3,4$, is tire lateral force.

6. Equation (58) for the vehicle yaw motion

$$
\begin{aligned}
\sum M=I_{z} \dot{\omega} & =b\left(F_{y 3}+F_{y 4}\right) \cos \delta_{r}-a\left(F_{y 1}+F_{y 2}\right) \cos \delta_{f} \\
& -\frac{B}{2}\left(F_{y 2}-F_{y 1}\right) \sin \delta_{r}-\frac{B}{2}\left(F_{y 4}+F_{y 3}\right) \sin \delta_{f} \\
& +M_{z 1}+M_{z 2}+M_{z 3}+M_{z 4}
\end{aligned}
$$

where $M_{z i}, i=1,2,3,4$ is tire self-aligning moment.

Thus, Equation (59) can be expressed as follows.

$$
\mathrm{RI}_{f u l l}=\frac{m_{u 3} \ddot{z}_{w 3}+F_{s 3}+m_{u 3} g+m_{u} \ddot{z}_{w 4}+F_{s 4}+m_{u 4} g-m_{u 1} \ddot{z}_{w 1}-F_{s 1}-m_{u 1} g-m_{u 2} \ddot{z}_{w 2}-F_{s 2}-m_{u 2} g}{m_{u 3} \ddot{z}_{w 3}+F_{s 3}+m_{u 3} g+m_{u 4} \ddot{z}_{w 4}+F_{s 4}+m_{u 4} g-m_{u 1} \ddot{z}_{w 1}-F_{s 1}-m_{u 1} g-m_{u 2} \ddot{z}_{w 2}-F_{s 2}-m_{u 2} g}
$$

\section{Simulation and Validation}

To validate the two proposed models, an industrial standard vehicle dynamics simulation software, CARSIM ${ }^{\circledR}$ was used to carry out simulations $[16,19,20]$. A standard SUV model was chosen from CARSIM ${ }^{\circledR}$ vehicle models as shown in Figure 8. Simulation and validation results of vehicle roll behavior were carried out under steering wheel (SW) input $10^{\circ}$ condition as an example case to facilitate better analysis of vehicle roll behavior.

Based on the above analysis, half-car and full-car models proposed in Section 4 were simulated in MATLAB to study performance of vehicle roll behavior with or without road excitation (two representatives). It is assumed that the tire does not loose ground contact. Here, the J-turn maneuver [15] was utilized to illustrate roll behavior for steering wheel at $10^{\circ}$ at a velocity of $80 \mathrm{~km} / \mathrm{h}$ with presence of road excitation. It was concluded from the results vehicle roll behavior mainly depends on roll angle, roll rate, and yaw rate. It should be noted that roll angle is variable under varying steering wheel input, and roll angle can be seen as a reference validation for vehicle roll behavior. 


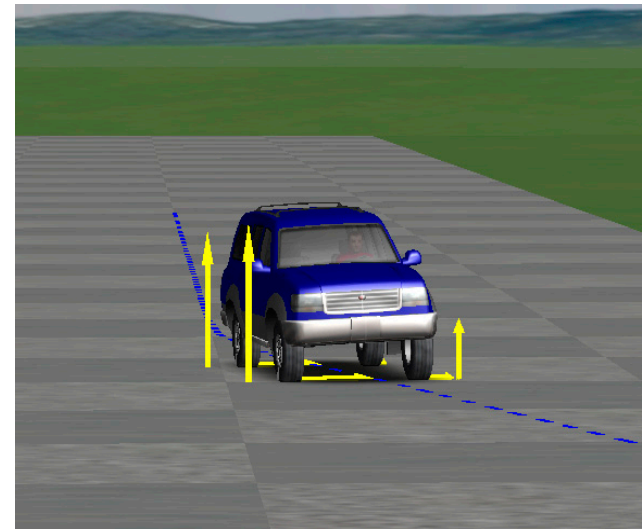

(a)

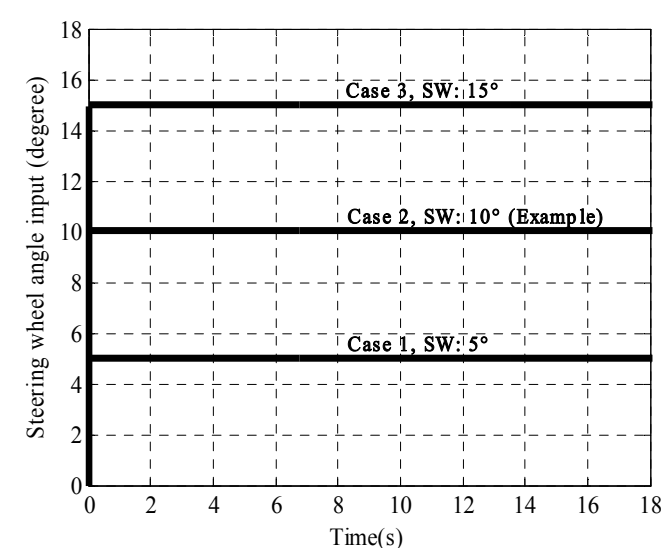

(b)

Figure 8. CARSIM simulation of roll behavior under various road excitation conditions. (a) Animation Screen. (b) Steering wheel input.

\subsection{Roll Behavior without Road Excitation}

Here, using vehicle dynamics model from Section 4, performance of vehicle roll behavior is simulated without presence of road input. Initial conditions used in the simulation are listed in Tables 1 and 2. Corresponding performance of roll behavior result parameters are shown in Figure 9. It can be seen from Figure 9 that without road excitation, half-car and full-car model are approximately equivalent. The E-Class (SUV) level car model in CARSIM ${ }^{\circledR}$ was used as benchmark results. Calculations carried out in MATLAB were found to be consistent with the CARSIM data. This suggests that vehicle dynamics model presented in Section 4 can be considered accurate to depict system dynamics under this condition.

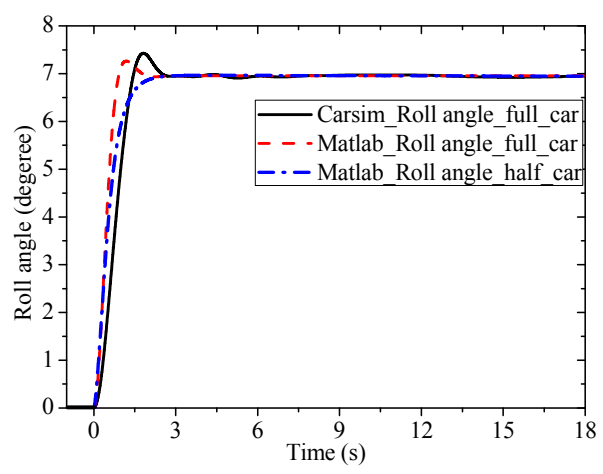

(a)

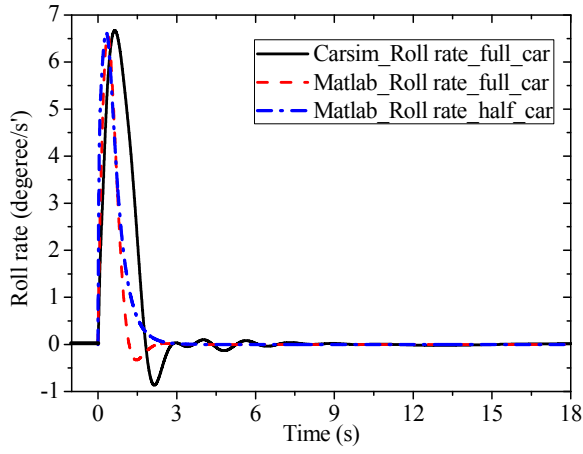

(b)

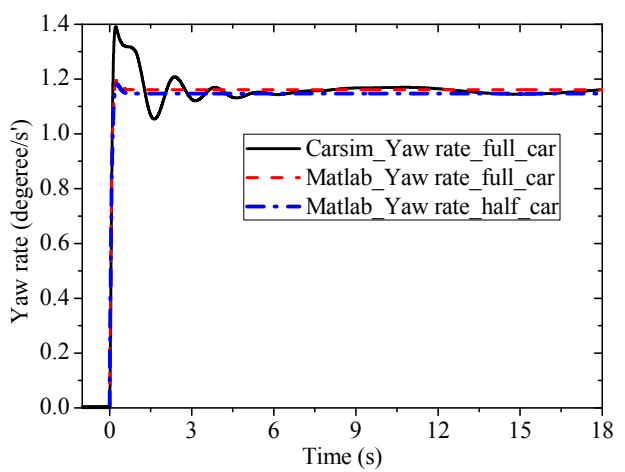

(c)

Figure 9. Results without road excitation (steering wheel angle was $10^{\circ}$ at $80 \mathrm{~km} / \mathrm{h}$ ). (a) Roll angle; (b) Roll rate; (c) Yaw rate. 


\subsection{Considering Road Excitation}

Case1: Level ISO- $A$ road excitation

Based on the vehicle dynamics model presented in Section 4, performance of vehicle roll behavior was also computed considering level ISO- $A$ road excitation. Roll angle, roll rate, and yaw rate for roll behavior are shown in Figure 10. From the results, it can be seen that with road excitation, vehicle roll responses are different under level ISO- $A$ road excitation. With $E$-Class (SUV) level car model in CARSIM $^{\circledR}$ as a benchmark, simulation data of 9-DOF full-car model was found to be consistent with CARSIM data, i.e., half-car roll model and full-car roll model are no more equivalent.

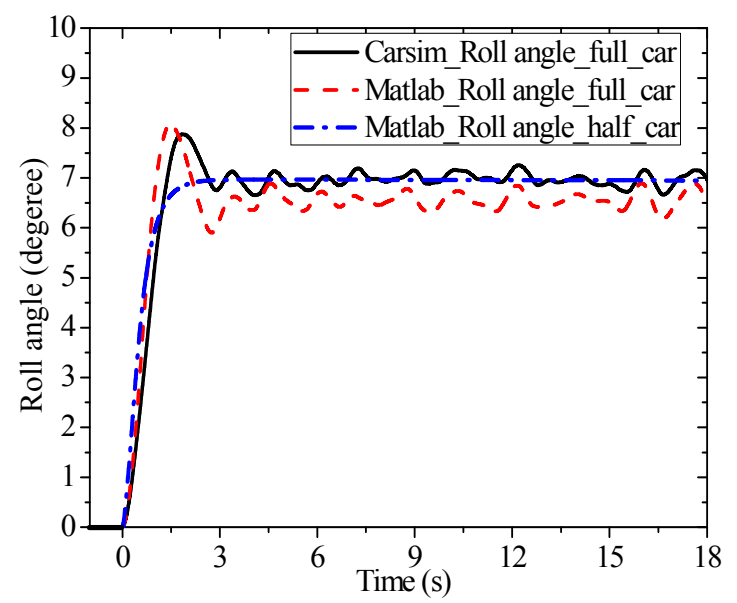

(a)

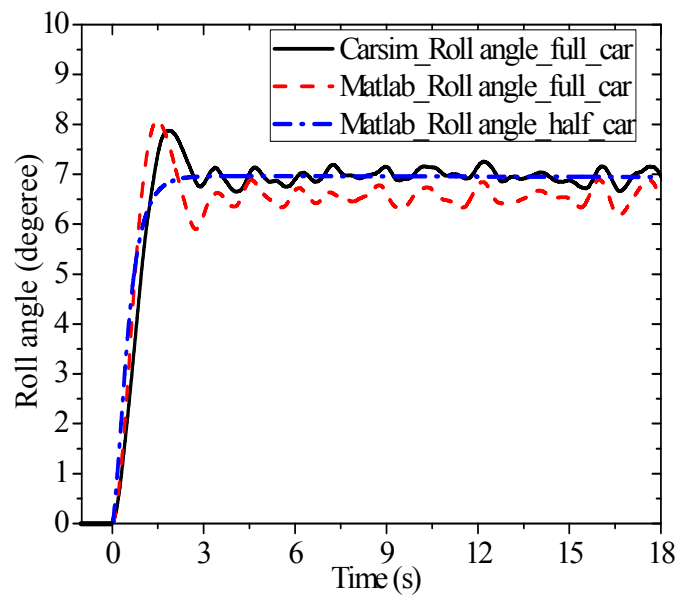

(b)

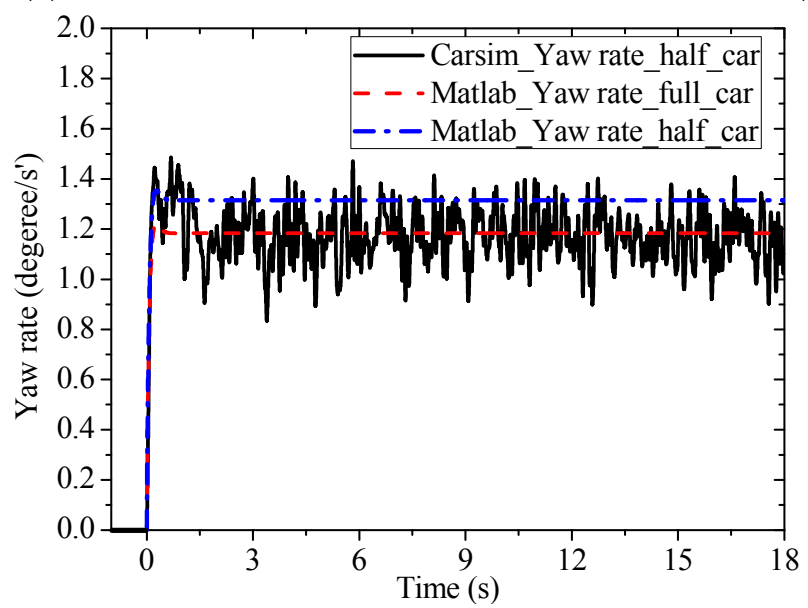

(c)

Figure 10. Results with road Level ISO- $A$ excitation (steering wheel angle was $10^{\circ}$ at $80 \mathrm{~km} / \mathrm{h}$ ). (a) Roll angle; (b) Roll rate; (c) Yaw rate.

\section{Case 2: Level ISO-C road excitation}

For level ISO-C road excitation case, roll angle, roll rate, and yaw rate for roll behavior are shown in Figure 11. It can be seen from the results that vehicle response for different dynamics models have significant impact on roll behavior under level ISO- $C$ road excitation, and influence of road excitation cannot be ignored in this situation [21-27]. 


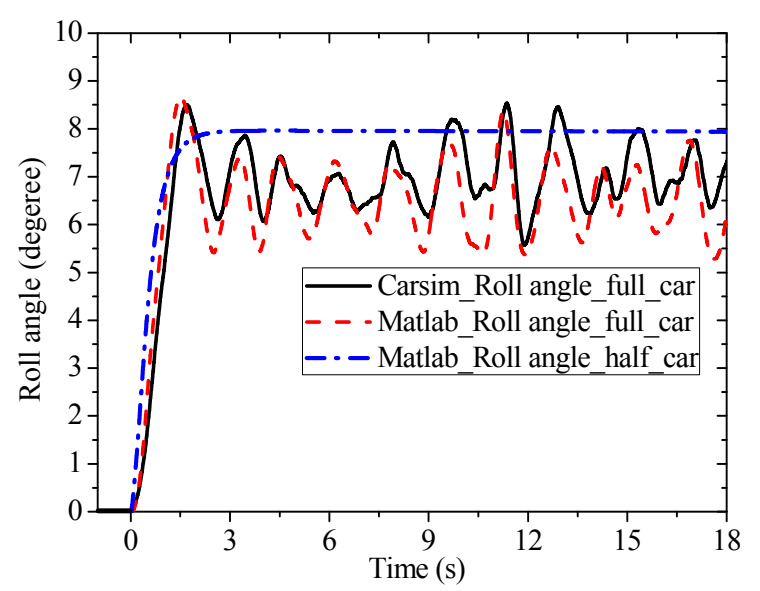

(a)

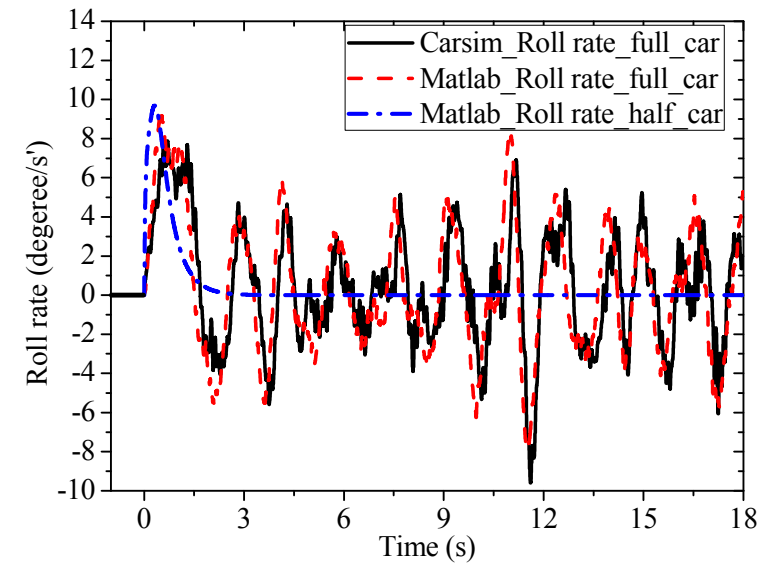

(b)

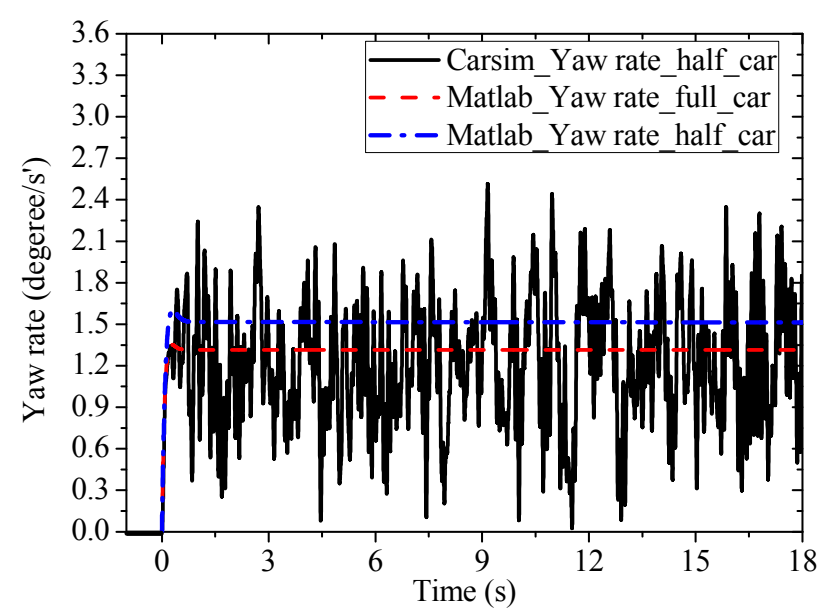

(c)

Figure 11. Results with road Level ISO-C excitation (steering wheel angle was $10^{\circ}$ at $80 \mathrm{~km} / \mathrm{h}$ ). (a) Roll angle, (b) Roll rate, (c) Yaw rate.

To further illustrate difference between 6-DOF and 9-DOF models with road excitation and various steering wheel inputs, vehicle responses were statistically analyzed. Previous research divided statistical parameters into dimensional parameters and non-dimensional parameters [21]. Dimensional parameters such as mean value, variance, maximum, etc., are used to depict steady stochastic processes especially suitable for statistical process description. Non-dimensional parameters, including Kurtosis, Crest factor, Clearance factor, etc., are utilized to describe transient processes, especially suitable for non-statistical process description. Vehicle steering wheel input is a transient response; due to this non-dimensional parameters should be adopted to study vehicle responses. Five widely applied features that suitable for depicting these temporary characteristics as listed in Table $4[22,23]$. Parameter $F_{1}$ and $F_{4}$ may indicate distribution characteristics. Parameters $F_{2} \sim F_{3}, F_{5}$ represent influence of impact or impulse input. 
Table 4. Statistics feature parameters.

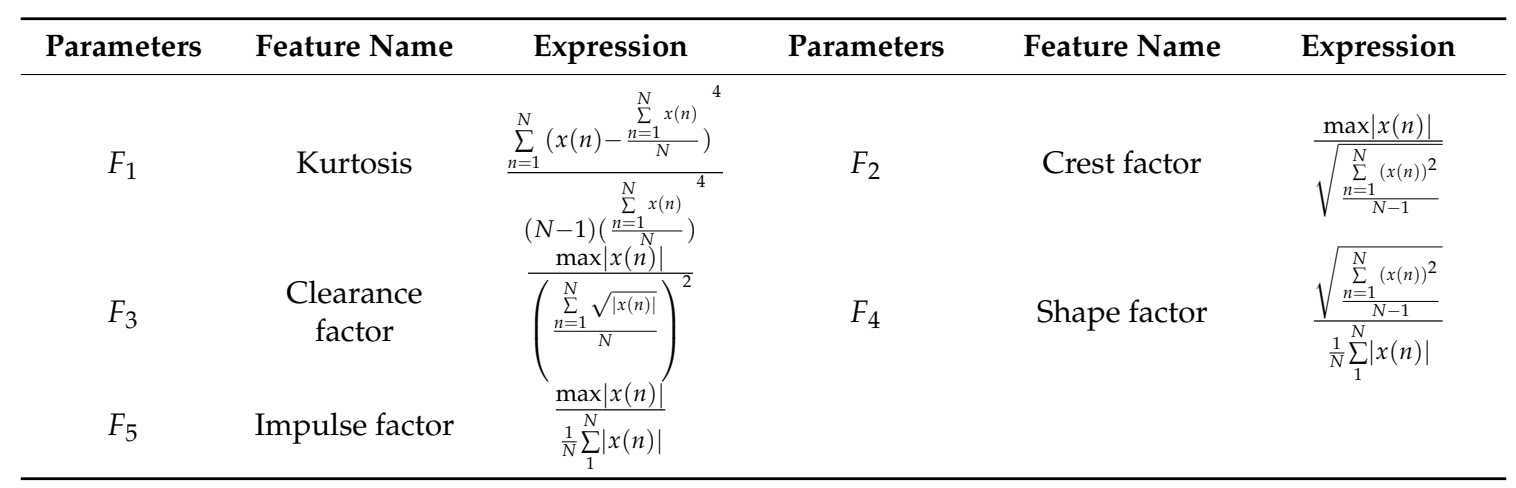

To illustrate error in different dynamics models, with E-Class (SUV) level car model in CARSIM $^{\circledR}$ as a benchmark, accuracy of proposed models and comparison results are summarized in Tables 5 and 6.

Table 5. Simulation accuracy of comparing 6-DOF model and CARSIM ${ }^{\circledR}$ with steering wheel $10^{\circ}$ input.

\begin{tabular}{ccccccc}
\hline Road Excitation & \multicolumn{3}{c}{ Level ISO- $A$ Excitation } & \multicolumn{2}{c}{ Level ISO- $C$ Excitation } \\
\hline & \multicolumn{3}{c}{ Accuracy of state calculation/\% } \\
& Roll angle & Roll rate & Yaw rate & Roll angle & Roll rate & Yaw rate \\
\hline$F_{1}$ (Kurtosis) & 97.7 & 46.5 & 97.0 & 93.5 & 11.7 & 70.2 \\
$F_{2}$ (Crest factor) & 86.8 & 73.2 & 83.9 & 81.5 & 43.3 & 54.1 \\
$F_{3}$ (Clearance factor) & 88.4 & 14.3 & 65.0 & 79.2 & 1.98 & 40.8 \\
$F_{4}$ (Shape factor) & 95.5 & 45.3 & 99.6 & 95.6 & 31.1 & 94.1 \\
$F_{5}$ (Impulse factor) & 88.4 & 33.2 & 83.6 & 80.4 & 13.4 & 50.9 \\
\hline
\end{tabular}

Table 6. Simulation accuracy of comparing 9-DOF model and CARSIM ${ }^{\circledR}$ with steering wheel $10^{\circ}$ input.

\begin{tabular}{ccccccc}
\hline Road Excitation & \multicolumn{3}{c}{ Level ISO- $\boldsymbol{A}$ Excitation } & \multicolumn{2}{c}{ Level ISO- $\boldsymbol{C}$ Excitation } \\
\hline & \multicolumn{3}{c}{ Accuracy of state calculation $\%$} & & \\
& Roll angle & Roll rate & Yaw rate & Roll angle & Roll rate & Yaw rate \\
\hline$F_{1}$ (Kurtosis) & 100 & 81.5 & 98.0 & 99.5 & 89.1 & 70.2 \\
$F_{2}$ (Crest factor) & 91.8 & 88.1 & 83.9 & 94.5 & 97.7 & 54.8 \\
$F_{3}$ (Clearance factor) & 89.2 & 94.9 & 73.1 & 91.1 & 80.9 & 45.9 \\
$F_{4}$ (Shape factor) & 99.8 & 98.7 & 99.6 & 99.6 & 97.4 & 94.1 \\
$F_{5}$ (Impulse factor) & 92.0 & 87.0 & 84.6 & 94.9 & 99.8 & 55.7 \\
\hline
\end{tabular}

Tables 5 and 6 show that different dynamics models have significant impact on the calculation accuracy, and higher accuracy using 9-DOF model can be obtained when coupling relationships exists between road excitation and vehicle dynamics.

\subsection{Disscussion}

From results in Figure 6, it can be seen that under identical vertical loads, when slip angle was smaller than $0.08 \mathrm{rad}$, lateral force on front rear tires increases linearly with increase in slip angle. However, when slip angle was larger than $0.08 \mathrm{rad}$, rate of lateral force increment gradually slows down, and relationship with slip angle is no longer linear. In addition, for identical slip angles, a larger vertical load was accompanied by a larger lateral force. Thus, for the tire model, lateral force is a function of slip angle and vertical load. Relationships between slip angle and vertical load were nonlinear [18]. This leads to nonlinear behavior of tire lateral forces under various steering wheel inputs. 
To further illustrate superiority of the proposed model, $5^{\circ}$ and $15^{\circ}$ steering wheel input situations were also simulated. Similar results were obtained without road excitation, i.e., 6-DOF half-car model and 9-DOF full-car model are approximately equivalent under these conditions. However, 6-DOF model and 9-DOF model have significant differences with road input. Corresponding simulation results for different steering wheel inputs and various road excitations are shown in Tables 7-10, which are described as shown in Figure 12. In Figure 12a, feature $F_{1}$, comparison of 6-DOF and 9-DOF models for road level ISO- $A / C$ excitation is shown. It can be seen that accuracy of vehicle responses were higher under road level ISO- $A$ excitation than road level ISO- $C$, i.e., higher road level lead to higher error. Roll angle and roll rate accuracy for vehicle responses of 6-DOF model was a maximum of $60 \%$ under road level ISO $-A / C$ excitation. Roll angle and roll rate calculation accuracy for vehicle responses of 9-DOF model was $85 \%$ under road level ISO- $A$ / $C$ excitation. With increase of the steering wheel input, as in the case of $F_{2}$, accuracy for 6-DOF model was a maximum of $58 \%$ under road level ISO- $A / C$ excitation. However, for a 9-DOF model accuracy declined at a slower rate than 6-DOF model as shown in Figure 12b. From $F_{3}$ perspective, an increase in road level resulted in accuracy for vehicle responses of 6-DOF and 9-DOF model to reach a maximum of $90 \%$ under road level ISO- $A / C$ excitation. However, for a 6-DOF model accuracy declined at a faster rate than 9-DOF model as shown in Figure 12c. Further, from $F_{4}$ and $F_{5}$ perspectives, Figure 12d,e show that accuracy of 9-DOF model vehicle responses are higher under road level ISO-C excitation and steering wheel input $15^{\circ}$ than 6-DOF model vehicle responses under road level ISO- $A$ excitation and steering wheel input $5^{\circ}$.

Table 7. Simulation accuracy of comparing 6-DOF model and CARSIM ${ }^{\circledR}$ with steering wheel $5^{\circ}$ input.

\begin{tabular}{ccccccc}
\hline Road Excitation & \multicolumn{3}{c}{ Level ISO- $A$ Excitation } & \multicolumn{2}{c}{ Level ISO- $C$ Excitation } \\
\hline & \multicolumn{3}{c}{ Accuracy of state calculation/\% } \\
& Roll angle & Roll rate & Yaw rate & Roll angle & Roll rate & Yaw rate \\
\hline$F_{1}$ (Kurtosis) & 98.2 & 28.5 & 91.7 & 88.1 & 53.6 & 53.3 \\
$F_{2}$ (Crest factor) & 92.4 & 65.9 & 73.6 & 70.1 & 39.3 & 42.7 \\
$F_{3}$ (Clearance factor) & 79.9 & 80.5 & 56.5 & 77.1 & 11.6 & 31.1 \\
$F_{4}$ (Shape factor) & 99.4 & 37.1 & 98.8 & 97.0 & 31.2 & 88.1 \\
$F_{5}$ (Impulse factor) & 91.9 & 24.5 & 72.7 & 68.0 & 12.2 & 37.7 \\
\hline
\end{tabular}

Table 8. Simulation accuracy of comparing 9-DOF model and CARSIM ${ }^{\circledR}$ with steering wheel $5^{\circ}$ input.

\begin{tabular}{ccccccc}
\hline Road Excitation & \multicolumn{3}{c}{ Level ISO- $\boldsymbol{A}$ Excitation } & \multicolumn{2}{c}{ Level ISO-C Excitation } \\
\hline & \multicolumn{3}{c}{ Accuracy of state calculation/\% } \\
& Roll angle & Roll rate & Yaw rate & Roll angle & Roll rate & Yaw rate \\
\hline$F_{1}$ (Kurtosis) & 99.8 & 96.0 & 91.8 & 94.0 & 73.9 & 53.3 \\
$F_{2}$ (Crest factor) & 87.8 & 94.1 & 71.7 & 95.4 & 91.8 & 41.7 \\
$F_{3}$ (Clearance factor) & 72.1 & 67.2 & 63.2 & 75.7 & 66.4 & 34.7 \\
$F_{4}$ (Shape factor) & 99.8 & 86.2 & 98.8 & 99.8 & 95.3 & 88.1 \\
$F_{5}$ (Impulse factor) & 88.0 & 87.6 & 70.8 & 95.4 & 96.0 & 36.7 \\
\hline
\end{tabular}

Table 9. Simulation accuracy of comparing 6-DOF model and CARSIM ${ }^{\circledR}$ with steering wheel $15^{\circ}$ input.

\begin{tabular}{ccccccc}
\hline Road Excitation & \multicolumn{3}{c}{ Level ISO- $\boldsymbol{A}$ Excitation } & \multicolumn{2}{c}{ Level ISO-C Excitation } \\
\hline & \multicolumn{3}{c}{ Accuracy of state calculation $/ \%$} \\
& Roll angle & Roll rate & Yaw rate & Roll angle & Roll rate & Yaw rate \\
\hline$F_{1}$ (Kurtosis) & 78.9 & 58.1 & 78.1 & 84.8 & 13.0 & 70.3 \\
$F_{2}$ (Crest factor) & 85.0 & 79.3 & 84.8 & 79.3 & 52.9 & 58.4 \\
$F_{3}$ (Clearance factor) & 70.3 & 20.8 & 62.5 & 64.7 & 3.11 & 42.6 \\
$F_{4}$ (Shape factor) & 79.6 & 50.3 & 79.7 & 79.0 & 31.3 & 76.8 \\
$F_{5}$ (Impulse factor) & 84.7 & 39.9 & 84.6 & 78.5 & 16.5 & 56.5 \\
\hline
\end{tabular}


Table 10. Simulation accuracy of comparing 9-DOF model and CARSIM ${ }^{\circledR}$ with steering wheel $15^{\circ}$ input.

\begin{tabular}{ccccccc}
\hline Road Excitation & \multicolumn{3}{c}{ Level ISO- $\boldsymbol{A}$ Excitation } & \multicolumn{2}{c}{ Level ISO- $\boldsymbol{C}$ Excitation } \\
\hline & \multicolumn{3}{c}{ Accuracy of state calculation/\% } & & \\
& Roll angle & Roll rate & Yaw rate & Roll angle & Roll rate & Yaw rate \\
\hline$F_{1}$ (Kurtosis) & 99.8 & 86.9 & 98.2 & 98.3 & 77.4 & 80.3 \\
$F_{2}$ (Crest factor) & 96.3 & 92.0 & 83.1 & 99.3 & 91.4 & 77.2 \\
$F_{3}$ (Clearance factor) & 91.1 & 95.2 & 71.2 & 87.6 & 95.3 & 78.5 \\
$F_{4}$ (Shape factor) & 99.9 & 94.2 & 99.8 & 99.7 & 97.4 & 96.8 \\
$F_{5}$ (Impulse factor) & 96.4 & 86.7 & 82.9 & 99.6 & 88.9 & 85.3 \\
\hline
\end{tabular}

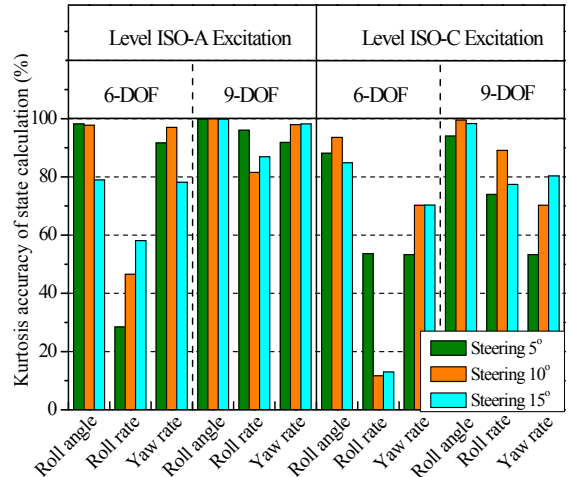

(a)

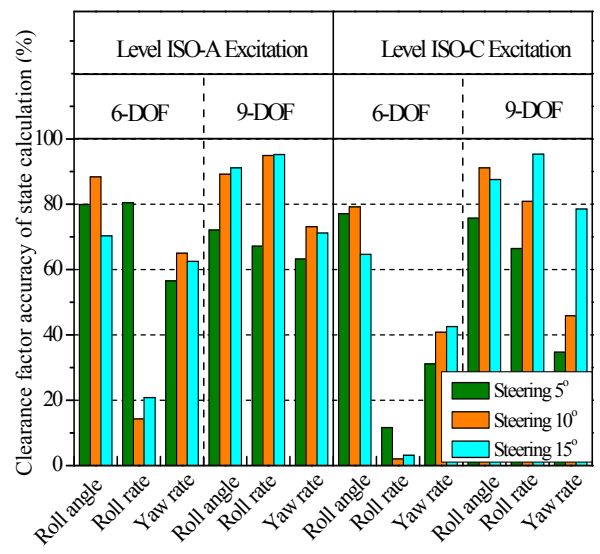

(c)

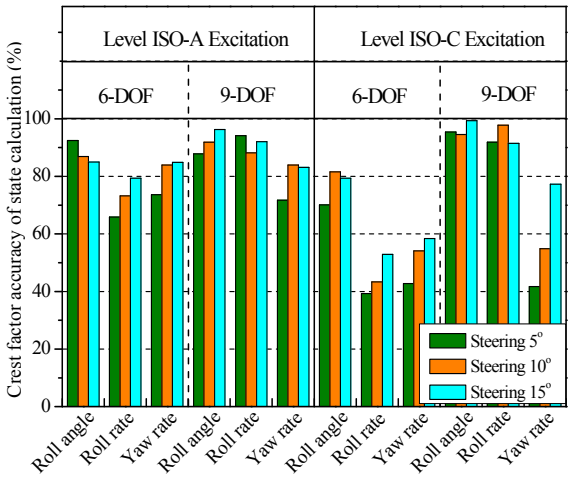

(b)

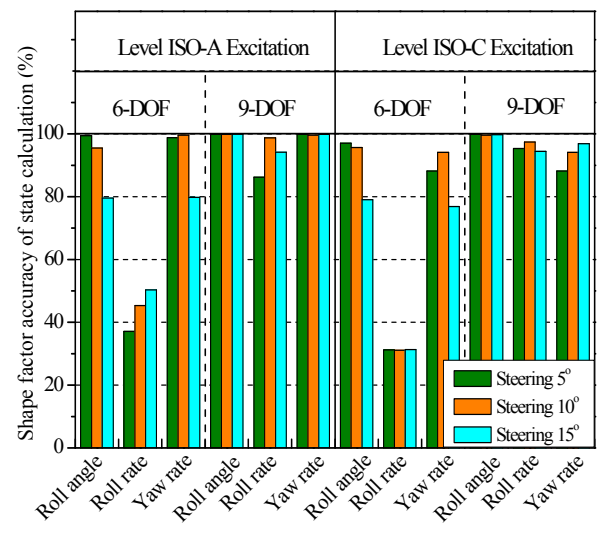

(d)

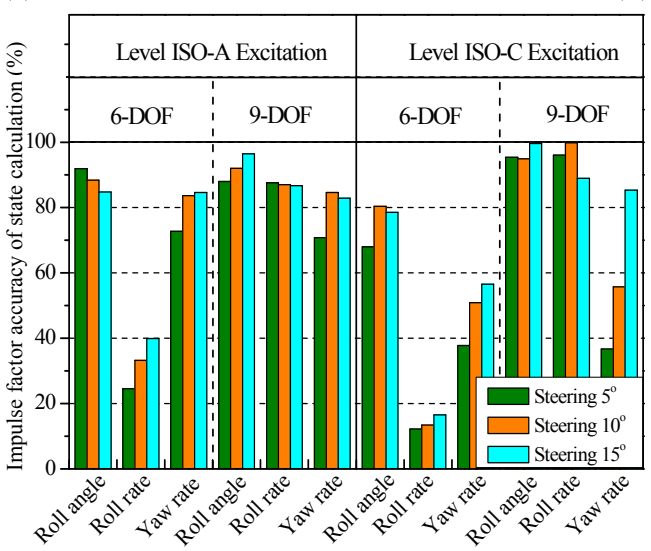

(e)

Figure 12. Accuracy of statistical features for vehicle state calculations using 6-DOF and 9-DOF models under road Level ISO- $A / C$ excitation and steering wheel $5^{\circ}, 10^{\circ}$ and $15^{\circ}$ conditions. (a) Kurtosis, (b) Crest factor, (c) Clearance factor, (d) Shape factor, (e) Impulse factor. 
Based on the above analysis, simulation results show that accuracy of statistical features calculation for 6-DOF model reached a maximum of $65 \%$ for all situations. Lower accuracy of statistical features follows increase in the angle of steering wheel input; accuracy of statistical features calculated for 9-DOF model was higher than $85 \%$.

Comparison of simulation results from MATLAB and CARSIM ${ }^{\circledR}$ allows verification of the proposed 9-DOF full-car model for roll behavior with or without road excitation condition. A 6-DOF half-car model was found to be suitable in conditions without road excitation. Influence of vehicle model on roll behavior should be adopted for the full-car model while analyzing vehicle roll behaviors with large steering wheel input and considering road excitation.

\section{Conclusions}

In this paper, performance of vehicle roll behavior under various road excitation and steering wheel inputs was studied using 6-DOF half-car and 9-DOF full-car models. With the proposed method, influence of half-car and full-car models on vehicle roll behavior and coupling relationships between vehicle vertical and lateral response was comprehensively studied. The main conclusions are as follows:

1. Based on the generating theories, a 3-D road profile model was first developed with road level ISO- $A / C$ as the half-car and full-car dynamics model input. State response of vehicle roll behavior relationships between road excitation and steering wheel input were calculated with half-car and full-car models. From the results, it was concluded that road excitation and steering wheel input have a significant influence on vehicle roll behaviors, i.e., 6-DOF model was suitable for small steering wheel input without road excitation. Average accuracy of this model was determined to be a maximum of $65 \%$. A 9-DOF model was more accurate for large steering input with road excitation with an average accuracy higher than $85 \%$.

2. Calculated vehicle response of vehicle roll behavior was validated using CARSIM $^{\circledR}$. Compared to calculation results, CARSIM ${ }^{\circledR}$ simulation results showed that proposed half-car model can provide a satisfying result without road excitation. However, full-car model can provide better description of system dynamics under various road excitation and large steering wheel input conditions to further validate the conclusions.

In the future, the proposed model will be applied to an actual road profile and a practical full-car will be realized using the proposed 9 DOF full-car model. In addition, our research will extend to state estimation and control of a full-car nonlinear suspension system and focus on application of these results for improving vehicle performance, especially on the aspects of ride comfort and road handling.

Acknowledgments: This work was supported by the National Natural Science Foundation of China (Grant No. U1564210), Innovative Talent Support Program for Post-Doctorate of China (Grant No. BX201600017) and China Postdoctoral Science Foundation (Grant No. 2016M600934).

Author Contributions: Zhen-Feng Wang and Ye-Chen Qin conceived and designed the simulations; Zhen-Feng Wang wrote the paper and analyzed the data; and Ye-Chen Qin, Liang Gu, Ming-Ming Dong, Jagat-Jyoti Rath and Bin Bai provided some suggestions and revised the paper.

Conflicts of Interest: The authors declare no conflict of interest.

\section{References}

1. Whitehead, R.; Travis, W.; Bevly, M.D.; Flowers, G. A Study of the Effect of Various Vehicle Properties on Rollover Propensity; SAE Technical Paper; SAE International: Detroit, MI, USA, 2004.

2. Yim, S. Design of a preview controller for vehicle rollover prevention. IEEE Trans. Veh. Technol. 2011, 60, 4217-4226. [CrossRef]

3. Yi, K.Y.; Yoon, J.Y.; Kim, D.S. Model-based estimation of vehicle roll state for detection of impending vehicle rollover. In Proceedings of the 2007 American Control Conference, New York, NY, USA, 9-13 July 2007; Volume 1, pp. 1624-1629. 
4. Rajamani, R.; Piyabongkan, D.; Tsourapas, V.; Lew, J.Y. Real-time estimation of roll angle and CG hight for active rollover prevention applications. In Proceedings of the 2009 American Control Conference, St. Louis, MO, USA, 10-12 June 2009; Volume 1, pp. 433-435.

5. Rajamani, R.; Piyabongkan, D.; Tsourapas, V.; Lew, J.Y. Parameter and state estimation in vehicle roll dynamics. IEEE Trans. Intell. Transp. Syst. 2011, 12, 1558-1567. [CrossRef]

6. Chen, B.C.; Peng, H. Differential-Braking-Based rollover prevention for sport utility vehicles with human-in-the-loop evaluations. Veh. Syst. Dyn. 2001, 36, 359-389. [CrossRef]

7. Larish, C.; Piyabongkan, D.; Tsourapas, V.; Rajamani, R. A new predictive lateral load transfer ratio for rollover prevention systems. IEEE Trans. Veh. Technol. 2013, 62, 2928-2936. [CrossRef]

8. Imine, H.; Benallegue, A.; Madani, T.; Srairi, S. Rollover risk prediction of heavy vehicle using high-order sliding-mode observer: Experimental results. IEEE Trans. Veh. Technol. 2014, 63, 2533-3543. [CrossRef]

9. Van der Westhuizen, S.F.; Els, P.S. Slow active suspension control for rollover prevention. J. Terramech. 2013, 50, 29-36. [CrossRef]

10. ISO. Mechanical Vibration-Road Surface Profiles-Reporting of Measured Data; ISO 8601-1995; International Organization for Standardization: Geneva, Switzerland, 1995.

11. Michelberger, P.; Palkovics, L.; Bokor, J. Robust design of active suspension system. Int. J. Veh. Des. 1993, 14, 145-165.

12. Wu, Z.C.; Chen, S.Z.; Yang, L. Model of Road Roughness in Time Domain Based on Rational Function. Trans. Beijing Inst. Technol. 2009, 29, 795-798.

13. Qin, Y.C.; Dong, M.M.; Langari, R.; Gu, L.; Guan, J.F. Adaptive hybrid control of vehicle semiactive suspension based on road profile estimation. Shock Vib. 2015, 2015. [CrossRef]

14. Detweiler, Z.R.; Ferris, J.B. Interpolation methods for high-fidelity three-dimensional terrain surfaces. J. Terramech. 2011, 47, 209-217. [CrossRef]

15. Rajamani, R. Vehicle Dynamics and Control, 2nd ed.; Springer: New York, NY, USA, 2012.

16. Phanomchoeng, G.; Rajamani, R. New rollover index for the detection of tripped and untripped rollovers. IEEE Trans. Ind. Electron. 2013, 60, 4726-4737. [CrossRef]

17. Pacejia, H.B. Tyre and Vehicle Dynamics; Butterworth-Heinemann: Oxford, UK, 2002.

18. Tan, D.; Lu, C. The influence of the magnetic force generated by the in-wheel motor on the vertical and lateral coupling dynamics of electric vehicles. IEEE Trans. Veh. Technol. 2016, 65, 4655-4668. [CrossRef]

19. Rath, J.J.; Defoort, M.; Karimi, H.R.; Veluvolu, K.C. Output feed-back active suspension control with higher order terminal sliding mode. IEEE Trans. Ind. Electron. 2017, 64, 1392-1403. [CrossRef]

20. Rath, J.J.; Defoort, M.; Veluvolu, K.C. Rollover index estimation in the presence of sensor faults, unknown inputs, and uncertainties. IEEE Trans. Intell. Transp. Syst. 2016, 17, 2949-2959. [CrossRef]

21. Palla, A.; Gnecco, I.; Lanza, L.G. Non-dimensional design parameters and performance assessment of rainwater harvesting systems. J. Hydrol. 2011, 40, 65-76. [CrossRef]

22. Qin, Y.C.; Dong, M.M.; Zhao, F.; Gu, L. Road profile classification for vehicle semi-active suspension system based on adaptive neuro-fuzzy inference system. In Proceedings of the 2015 54th IEEE Conference on Decision and Control, Osaka, Japan, 15-18 December 2015; Volume 1, pp. 1533-1538.

23. Wang, Z.F.; Dong, M.M.; Qin, Y.C.; Du, Y.C.; Zhao, F.; Gu, L. Suspension system state estimation using adaptive Kalman filtering based on road classification. Veh. Syst. Dyn. 2016, 55, 371-398. [CrossRef]

24. Qin, Y.C.; Xiang, C.L.; Wang, Z.F.; Dong, M.M. Road excitation classification for semi-active suspension system based on system response. J. Vib. Control 2017. [CrossRef]

25. Zhao, F.; Ge, S.S.; Tu, F.W.; Qin, Y.C.; Dong, M.M. Adaptive neural network control for active suspension system with actuator saturation. IET Control Theory Appl. 2016, 14, 1696-1705. [CrossRef]

26. Qin, Y.C.; Zhao, F.; Wang, Z.F.; Gu, L.; Dong, M.M. Comprehensive analysis influence of controllable damper time delay on semi-active suspension control strategies. J. Vib. Acoust. 2017. [CrossRef]

27. Wang, Z.F.; Dong, M.M.; Zhao, W.P.; Gu, L. A novel tread model for tire modelling using experimental modal parameters. J. Vibroeng. 2017, 19, 1225-1240. [CrossRef]

(C) 2017 by the authors. Licensee MDPI, Basel, Switzerland. This article is an open access article distributed under the terms and conditions of the Creative Commons Attribution (CC BY) license (http://creativecommons.org/licenses/by/4.0/). 